\title{
NMHCs in a heavily polluted city in Northern China: Characteristics, effects on SOA potential, and source apportionment
}

\author{
Mengyao Qi ${ }^{1,2}$, Litao Wang ${ }^{1,2, *}$, Qing Wang ${ }^{1,2}$, Xiaohan Lu $^{1,2}$, Wei Wei ${ }^{3}$, Yu Wang ${ }^{1,2}$, Zhentong Liu ${ }^{1,2}$, \\ Jingyao Tan ${ }^{1,2}$, Yingying Liu ${ }^{1,2}$, and Ruiguang $\mathrm{Xu}^{1,2,4}$ \\ ${ }^{1}$ Department of Environmental Engineering, School of Energy and Environmental Engineering, Hebei University of Engineering, \\ Handan, China \\ ${ }^{2}$ Hebei Key Laboratory of Air Pollution Cause and Impact (preparatory), Handan, China \\ ${ }^{3}$ Department of Environmental Science and Engineering, Beijing University of Technology, Beijing, China \\ ${ }^{4}$ Institute of Earth Environment, Chinese Academy of Sciences, Xi'an, China
}

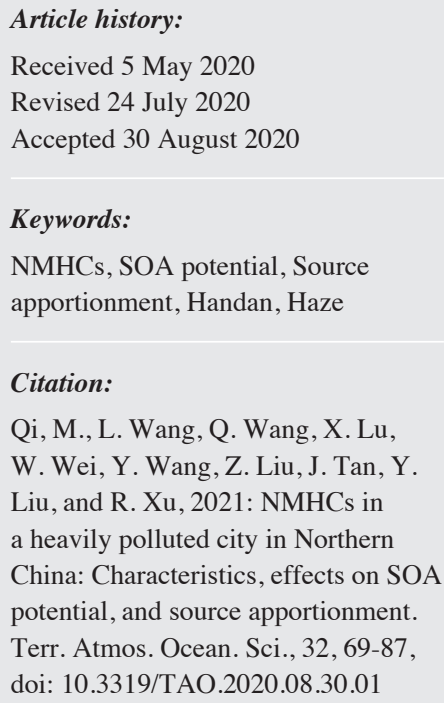

Qi, M., L. Wang, Q. Wang, X. Lu, W. Wei, Y. Wang, Z. Liu, J. Tan, Y. Liu, and R. Xu, 2021: NMHCs in a heavily polluted city in Northern China: Characteristics, effects on SOA potential, and source apportionment. Terr. Atmos. Ocean. Sci., 32, 69-87, doi: 10.3319/TAO.2020.08.30.01

\begin{abstract}
Non-methane hydrocarbons (NMHCs) plays an important role in haze events. This study focused on NMHCs characteristics, effects on secondary organic aerosol (SOA) and source apportionment in Handan in heavily polluted seasons, i.e., autumn (October 2017) and winter (January 2018) and their differences in non-haze and haze days. An online instrument (AMA GC5000) was used to monitor NMHCs in Handan firstly at the campus of Hebei University of Engineering. It was found that the average NMHCs concentrations were 41.45 and $57.56 \mathrm{ppb}$ in autumn and winter, respectively, which were higher than most investigated domestic and foreign megacities to the best of our knowledge. Alkanes was the largest contributor to NMHCs (45.4\%), and followed by alkenes, aromatics, and acetylene. In haze days, the concentrations of NMHCs and four categories increased far more in winter than those in autumn compared to non-haze days. The total SOA potential (SOAP) in winter (3364 $\left.\mu \mathrm{g} \mathrm{m}^{-3}\right)$ was higher than that in autumn $\left(2804 \mu \mathrm{g} \mathrm{m}^{-3}\right)$. The total SOAP was close in haze and non-haze days in autumn, while it was much higher in haze days in winter. Regardless of the variations of different periods, aromatics contributed most to the total SOAP, with contributions of $87-95 \%$, where toluene was the most contributed species. Combined the results of diagnostic ratios with positive matrix factorization (PMF) model, NMHCs of Handan was mainly contributed by traffic emissions and combustion events. Vehicle related (from 23.2 to $30.1 \%$ ) and industrial related source (from 13.7 to $26.7 \%$ ) may be major contributors to the haze pollution in autumn and winter, respectively.
\end{abstract}

\section{INTRODUCTION}

Non-methane hydrocarbons (NMHCs) is an important participant in atmospheric photochemical processes (Carter 1994). It includes many chemical species that have quite different chemical reactivity (Sonderfeld et al. 2016). NMHCs react with oxidants in the atmosphere (e.g., $\mathrm{OH}$ radical) and produce secondary pollutants, e.g., secondary organic aerosol (SOA) and ozone $\left(\mathrm{O}_{3}\right)$ (Carter 1994; Song and Shon 2014; Baudic et al. 2016; Schallhart et al. 2018). Huang et al. (2014) indicated that the contributions of SOA to $\mathrm{PM}_{2.5}$

\footnotetext{
* Corresponding author

E-mail:wanglitao@hebeu.edu.cn
}

could be as high as about $44-71 \%$ on average. Therefore, NMHCs plays an important role in $\mathrm{PM}_{2.5}$ formation and haze events. The main sources of NMHCs could be natural or anthropogenic, e.g., vegetation, volcanoes, and the decay of organic compounds derived from marine are major natural sources of NMHCs (Kaltsonoudis et al. 2016). Li et al. (2018a) listed 15 anthropogenic sources that accounted for more than $90 \%$ of the total emissions, i.e., power plant coal burning, industrial coal burning, residential coal burning, biomass burning, coking industry, petrochemical industry, iron and steel industry, diesel vehicles, gasoline vehicles, motorcycles, automobile coating, furniture coating, architectural coating, printing, and fuel oil evaporation. 
Most Chinese cities suffered from severe haze pollution in recent decades. Hebei is one of the top polluted provinces in China. In 2013, the State Council published the National Action Plan for Air Pollution Prevention and Control and the Hebei government also released the provincial Action Plan. After six years efforts, the air quality in Hebei Province had substantial improvement that the annual average $\mathrm{PM}_{2.5}$ concentration decreased from $138 \mu \mathrm{g} \mathrm{m}^{-3}$ in 2013 to $69 \mu \mathrm{g} \mathrm{m}^{-3}$ in 2018 , however, the concentration was still about 2.0 times of the national grade II standard $\left(35 \mu \mathrm{g} \mathrm{m}^{-3}\right)$. In 2013, 74 cities in Beijing-Tianjin-Hebei region (BTH), Yangtze River Delta (YRD), Pearl River Delta (PRD), and other key regions as well as provincial capitals and municipalities were separately listed according to their air quality comparing to the new standards (GB 3095-2012). Among these cities, Handan always ranked in the top ten polluted cities from 2013 to 2018 in the report from the Ministry of Ecology and Environment of China (MEE, http://www. mee.gov.cn/hjzl/zghjzkgb/lnzghjzkgb/).

Handan city, located in the southern edge of Hebei Province, is a typical industrial city with high population density. Steel and iron industry, metallurgical industry, and construction material industries, e.g., cement and glass, are its dominant industries. The location of Handan is in the intersectional area of four provinces (Hebei, Henan, Shanxi, Shandong). Those four provinces all have large quantities emissions of air pollutants ( $\mathrm{Li}$ et al. 2017a). In particular, the sum $\mathrm{PM}_{2.5}$ contribution of Henan, Shanxi and Shandong Province to Handan reached 26.2\% in 2014 (Chang et al. 2019). The terrain of Handan declines staircase from the west to the east, by an average gradient of $11.8 \%$ (http:// www.hd.gov.cn/zjhd/hdgk/). In addition, the Taihang mountain lies in the west of Handan, which may obstruct the west-east airflow transmission.

Most previous studies on Handan mainly focused on $\mathrm{PM}_{2.5}$ pollution (Ma et al. 2016; Meng et al. 2016; Zhang et al. 2018a). But very few studies aimed at $\mathrm{PM}_{2.5}$ precursors. It is reported that the percentages of $\mathrm{OC}$ and $\mathrm{SOA}$ in $\mathrm{PM}_{2.5}$ increased in the past five years after effective controls of inorganic pollutants (Zhao et al. 2019) and it is necessary to study on the characteristics of NMHCs and SOA pollution of Handan (Wang et al. 2014).

Previous studies on NMHCs were pursued mostly in megacities, e.g., Beijing, Guangzhou, Wuhan, etc. Li et al. (2020) continuously measured NMHCs in Beijing from March 2016 to January 2017, and the seasonal variations of concentrations, SOA potential (SOAP), ozone formation potential, and apportionment of local source (by PMF) and regional transport (by PSCF) were investigated, which is of great significance for providing references to guide the $\mathrm{PM}_{2.5}$ and $\mathrm{O}_{3}$ reduction policy formulation. Wei et al. (2018) analyzed volatile organic compounds (VOCs, referring to $\mathrm{C}_{2}-\mathrm{C}_{12}$ hydrocarbons) concentration, composition, chemi- cal degradation, and regional transport impact between haze and non-haze in July and December of 2015 in Beijing, through VOCs observation and Weather Research and Forecasting model coupled with Chemistry (WRF-Chem) simulation. Zou et al. (2015) simultaneously measured ozone, nitrogen oxides (NOx) and VOCs in Guangzhou from June 2011 to May 2012, and studied their characteristics, the effect on ozone photochemical production, and the relationship between VOC/NOx ratio and ozone formation. Hui et al. $(2018,2019)$ also continuously observed VOCs (102 volatile organic compounds) in Wuhan, and analyzed the characteristics, SOAP, and ozone formation potential and source contributions. According to the above studies, the alkanes always had the largest concentration, and the aromatics were important contributors to SOA. The PMF model was used to identify the local emission sources, and the contribution of regional transport to the NMHCs concentration should not be neglected. However, very few studies focused on the secondary pollution in Handan. Therefore, we pursued an online observation of NMHCs in Handan for the first time to understand the characteristics and impact of NMHCs in heavily polluted seasons.

The study aimed to explore the NMHCs characteristics, SOAP, and source contributions, moreover, we investigated their variations in non-haze and haze days, to support the comprehensive pollution control in heavily polluted days.

\section{MATERIAL AND METHOD}

\subsection{Sampling Sites and Its Representativeness}

Online monitoring of NMHCs was carried out in autumn (1 - 31 October 2017) and winter (1 - 31 January 2018) at Hebei University of Engineering (HEBEU) site, which located in the southeast of Handan. The sampling site is on the rooftop of Energy and Environmental Engineering Laboratory $\left(36.58^{\circ} \mathrm{N}, 114.51^{\circ} \mathrm{E}\right)$, about $12 \mathrm{~m}$ above the ground (Fig. 1). This site is considered as a typical mixed area of cultural and residential, and no obvious emission sources or tall buildings within the surrounding areas.

The representativeness of this sampling site was also proved by calculating the ratio of nitrogen monoxide (NO) and nitrogen dioxide $\left(\mathrm{NO}_{2}\right)$ (Baudic et al. 2016). Only when the ratio was below $1.5 \mathrm{ppb} \cdot \mathrm{ppb}^{-1}$, a station would be considered as an urban background site. The ratio of $\mathrm{NO}$ and $\mathrm{NO}_{2}$ which are 0.52 and 0.55 for autumn and winter, respectively (Table 1). Furthermore, most industrial area in Handan located in the northwest of the sampling site and the prevailing wind in autumn and winter are from northeast and northeast to east, respectively (see Fig. 1c). Therefore, the sampling site could represent the urban atmosphere without local influence of nearby industries, which is representative to support the study on urban pollution characteristic, source apportionment, and control policy. 


\subsection{Sampling Instrument}

\subsubsection{NMHCs}

NMHCs was measured by GC 5000 System from AMA Instruments (Germany), which included GC 5000 BTX, GC 5000 VOC, and DIM 200. The cores of this system are GC $5000 \mathrm{BTX}$, a high boiling point analyzer for $\mathrm{C}_{6}-\mathrm{C}_{12} \mathrm{NMHCs}$ species, and GC $5000 \mathrm{VOC}$, a low boiling point analyzer for $\mathrm{C}_{2}-\mathrm{C}_{6} \mathrm{NMHCs}$ species with two-stage enrichment. The instrument can measure 56 species including 29 alkanes, 10 alkenes, 16 aromatics, and acetylene (the only alkynes).

The analysis method of BTX and VOC is chromatography. A circulation will begin with sample gas flows into BTX and VOC oven, respectively and simultaneously. The sample line is purged with sample gas to make sure that current sample gas is available when starting sampling. Then a definite volume of sample is sucked through an enrichment tube which is filled with adsorbent materials. The enrichment tube temperature of BTX and VOC will be heated, and samples in BTX will be flushed onto the gas chromatographic capillary column, and samples in VOC will be flushed onto the focusing tube first and the focusing tube temperature will be heated in a very fast way. Then, thermally separation happens, and the sample gas will be flushed onto the gas chromatographic capillary column as well. Next, the separated species would be detected by FID system. The circulation goes every hour, and before next circulation, the enrichment and focusing tubes will be heated and cleaned by carrier gas and decrease to its set point.

The observation was continuously during monitoring period. Furthermore, to ensure the accuracy of concentration dataset, the calibration was pursued every month under the premise of stable detector. The standard gas, which contained 56 NMHCs species, met the criteria of Photochemical Assessment Monitoring Stations (PAMS), which was admitted by Environmental Protection Agency (US EPA), and was used to calibrate the $\mathrm{C}_{2}-\mathrm{C}_{12}$ NMHCs.

\subsubsection{Other Data}

Continuously monitoring of $\mathrm{NO}$ and $\mathrm{NO}_{2}$ was pursued by Model 42i (Thermo Fisher Scientific, USA) by

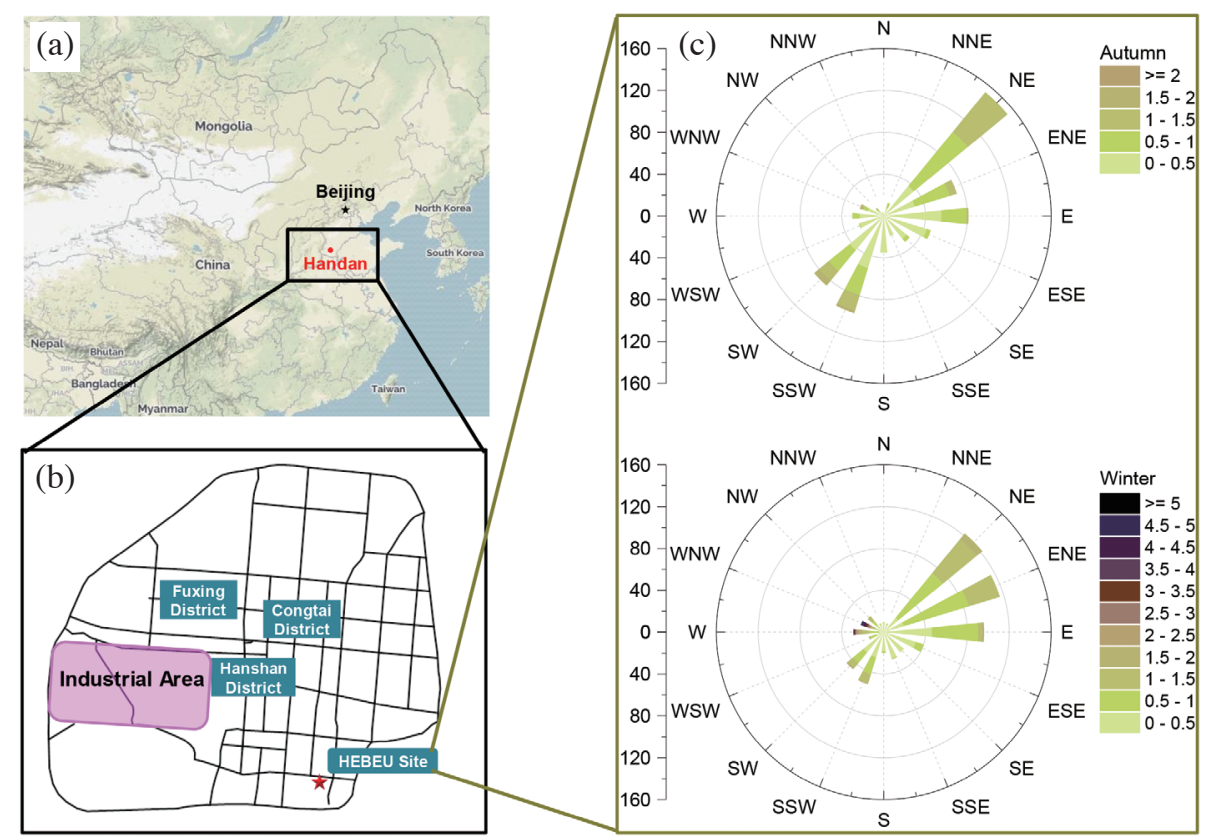

Fig. 1. (a) The location of Handan city, (b) urban Handan and the sampling site, and (c) wind roses of the sampling site in autumn and winter.

Table 1. $\mathrm{NO}$ and $\mathrm{NO}_{2}$ concentrations and their ratios in monitoring period in Handan.

\begin{tabular}{c|cc}
\hline & Autumn & Winter \\
\hline NO (ppb) & 14.1 & 9.1 \\
$\mathbf{N O}_{2}(\mathbf{p p b})$ & 27.2 & 16.7 \\
$\mathbf{N O} / \mathrm{NO}_{2}\left(\mathbf{p p b} \cdot \mathbf{p p b}^{-1}\right)$ & 0.52 & 0.55 \\
\hline
\end{tabular}


chemiluminescence method. Wind direction and wind speed were monitored by Swarco-lufft Instrument (Germany) and visibility (VIS) was measured by Brial (England). All these instruments are situated on the HEBEU site. Hourly and daily $\mathrm{PM}_{2.5}$ and $\mathrm{CO}$ concentrations were gathered from national air quality control station, which was also located in the campus of HEBEU, and the dataset was available in China National Environmental Monitoring Center (CNEMC).

\subsection{Secondary Organic Aerosol}

The method of SOAP calculation was developed by Derwent et al. (2010). Several previous studies in China also used this method (Hui et al. 2019; Li et al. 2020). The SOAP represents the propensity for an organic compound to form SOA relative to toluene, which is set to 100, and is calculated as Eq. (1) (Derwent et al. 2010). Toluene is identified as an important man-made precursor of SOA and its emission is well characterized (Kleindienst et al. 2007; $\mathrm{Hu}$ et al. 2008). The total SOAP is the sum of the SOAP values of all measured NMHC species, as shown in Eq. (2), where the $\mathrm{E}_{i}$ is the concentration of NMHC species. (Li et al. 2020).

$\mathrm{SOAP}_{i}=\frac{\text { Increment in SOA mass concentration with species } i}{\text { Increment in SOA with toluene }} \times 100$ (1)

$\mathrm{SOAP}=\sum \mathrm{E}_{i} \times \mathrm{SOAP}_{i}$

\subsection{Positive Matrix Factorization}

PMF (Positive Matrix Factorization) model is a receptor model which is widely applied to quantify source contributions of $\mathrm{PM}_{2.5}$ components and NMHCs species (Brown et al. 2007; Chen et al. 2014; Li et al. 2017b; Manousakas et al. 2017). The analytical approach of the model is to decompose a matrix of NMHCs sample data into two matrices: factor contributions $(\mathrm{G})$ and factor profiles $(\mathrm{F})$, which is viewed as a data matrix $\mathrm{x}$ of $i$ by $j$ dimensions. The $i$ is the number of samples and $j$ is the number of measured NMHCs species. Matrix $x_{i j}$ would be resolved by providing $p$ (the number of factors), with factor contribution ( $\mathrm{g}$ ), and factor profiles (f). The $\mathrm{e}_{i j}$ is the residual for each sample or species. This is summarized in Eq. (3). More details of the method were described by Paatero and Tapper (1994) and Paatero (1997). It is notable that $p$ is an critical parameter in PMF, which is estimated by $\mathrm{Q}$, scaled residuals, scatter plot, time series of predicted/observed species, and the physical meaning of factor profiles (USEPA 2014; Baudic et al. 2016).

$\mathrm{x}_{i j}=\sum_{k=1}^{p} \mathrm{~g}_{i k} \mathrm{f}_{k j}+\mathrm{e}_{i j}$
Continuously hourly data during monitoring period are applied to drive the PMF model. The input datasets in autumn and winter were different, that 32 species were used in autumn dataset and 26 species were used in winter dataset. The missing values were replaced by median concentration values. Uncertainties of missing value is four times to median concentration value, and uncertainties of other samples are calculated by Eq. (4), where the EF means error fraction, which referred as $10 \%$, and the MDL means the method detection limits of each NMHC species.

$\mathrm{Q}$ is a critical parameter for PMF, which is defined as Eq. (5). Here, $\mathrm{u}_{i j}$ is uncertainty. There are two kinds of $\mathrm{Q}$ in PMF running: Q (true) and Q (robust), which are goodness-of-fit parameters, but Q (true) calculated including all points and $\mathrm{Q}$ (robust) calculated excluding points not fit by the model. Because Q (robust) is not influenced by points that do not fit for PMF, it is a critical parameter for choosing the optimal run from the multiple runs.

$\mathrm{Unc}=\left\{\begin{array}{c}\frac{5}{6} \times \mathrm{MDL}, \text { con } \leq \mathrm{MDL} \\ \sqrt{(\mathrm{EF} \times \mathrm{con})^{2}+(0.5 \times \mathrm{MDL})^{2}}, \text { con }>\mathrm{MDL}\end{array}\right.$

$\mathrm{Q}=\sum_{i=1}^{n} \sum_{j=1}^{m}\left(\frac{\mathrm{x}_{i j}-\sum_{k=1}^{p} \mathrm{~g}_{i k} \mathrm{f}_{k j}}{\mathrm{u}_{i j}}\right)^{2}$

This study ran eight times with different $p$, which was in a range of $2-9$. The scaled residuals were in the range of $-3-3$, and the observed dataset fit well with the model predicted value. When the $\mathrm{Q}_{\text {true }} / \mathrm{Q}_{\text {excepted }}$ was close to 1.0, the factor number is more optimum (Baudic et al. 2016). According to Fig. 2, 4 and 8 are more appropriate than other numbers. However, when the factor number is 8 , not all source profiles can be defined. So, it is obviously concluded that the proper number of $p$ is 4 . The optimal solution varied with chemical transformations or process changes, which may lead to significant differences in factor profiles among PMF runs. It is necessary to access the stability of model results.

Three methods were used for evaluating the results: DISP, BS, BS-DISP, which identified rotation, random error of dataset, and their combined effect to the solution. The DISP results of this study were validated, for there were no error detected and no swap occurred when dQ were $4,8,15,25$. After running bootstrap with the minimum Pearson correlation coefficient $(\mathrm{R}=0.6)$, BS-DISP started running. The results of three methods confirmed that the solution is available.

\section{RESULTS}

\subsection{Characteristics of NMHCs}

\subsubsection{Concentrations and Components of NMHCs}

Table 2 summarizes the NMHCs concentrations in 
Handan in monitoring months, as well as the comparisons with those of other domestic and foreign cities. The concentrations of total NMHCs (TNMHCs) in Handan were 41.45 ppb in autumn (1 - 31 October 2017) and $57.56 \mathrm{ppb}$ in winter (1 - 31 January 2018). The concentration of alkanes in winter was higher than that in autumn and the concentrations of ethane and propane were both nearly 2 times to autumn, which may indicate more emissions of their potential sources.

Alkanes was the largest contributor to NMHCs among four categories (alkanes, alkenes, acetylene, aromatics), with an average concentration of $22.47 \mathrm{ppb}$ and accounting for $45.4 \%$ of TNMHCs, followed by alkenes (15.40 ppb), aromatics (7.33 ppb), and acetylene (4.27 ppb), accounting for $31.1,14.8,8.6 \%$ in monitoring days. Figure 3 shows the top 20 abundant NMHCs species in Handan, which accounted for about $90 \%$ of the total NMHCs concentrations. The 20 species contained 8 alkanes, 4 alkenes, 7 aromatics, and acetylene. The concentrations of 8 alkanes species accounted for 83.6 and $87.7 \%$ of the total alkanes in autumn and winter, and the 4 alkenes species accounted for 91.1 and $94.7 \%$ of the total alkenes in autumn and winter, respectively. The 7 aromatics represented about 82.7 and $82.3 \%$ of all measured aromatics species in autumn and winter. To simplify the expression, in the following sentences, the two numbers in parentheses represented the concentration in autumn (the former one) and winter (the latter one). In the 8 alkanes, the average concentrations of ethane (6.52 and $11.06 \mathrm{ppb})$, propane (2.97 and $4.77 \mathrm{ppb})$, i-pentane (1.86 and $1.64 \mathrm{ppb}$ ), and n-butane (1.69 and $2.03 \mathrm{ppb})$ were higher. In the 4 alkenes, the concentration of ethene were 9.29 and $15.39 \mathrm{ppb}$. Among the 7 aromatics, the concentrations of benzene and toluene were higher, which were $1.47,1.64$ ppb and 2.40, $2.11 \mathrm{ppb}$ in autumn and winter, respectively. Above all, $\mathrm{C}_{2}-\mathrm{C}_{5}$ alkanes, $\mathrm{C}_{2}-\mathrm{C}_{5}$ alkenes, acetylene, benzene and toluene are the most abundant species among four categories, which accounted for $34.9,25.7,8.4$, and $7.5 \%$ in autumn and $37.3,30.3,8.8$, and $7.8 \%$ in winter.

Because of differences in monitoring time, sites location and instruments in other studies, common species in close periods were compared with those in Handan (Table 2). The TNMHCs concentration was about 2 times to Beijing and Paris (Baudic et al. 2016; Yang et al. 2018), little higher than those in Tianjin and Nanjing (Liu et al. 2016; Shao et al. 2016), and close to those of Guangzhou, Yokohama, and Houston (Leuchner and Rappenglück 2010; Tiwari et al. 2010; Zou et al. 2015). The alkanes compositions in Handan were similar to those of Tianjin both in autumn and winter, a megacity in northern China, with dominated emissions from automobile exhaust (23.1\%), industrial emission (19.9\%), liquefied petroleum gas/natural gas (18.6\%), and combustion (10.6\%) (Liu et al. 2016). The alkenes concentration in Handan was 1.5 - 8.7 times to other cities no matter in autumn or in winter, which was caused by high concentration of ethene. Ethene was reported mainly from combustion and industrial area (Na et al. 2001; Hui et al. 2019). Furthermore, acetylene concentration in Handan was close to those in domestic cities and higher than that in Yokohama and Houston. The aromatics concentration in Handan in autumn and winter had few differences. The concentrations of benzene and toluene in winter were higher than those in autumn. Aromatics concentrations of Handan was lower than those in Guangzhou and Nanjing. However, the proportions of aromatics species in Handan were similar to those in Nanjing, with dominated sources of vehicular emission, industrial production, solvent use sources (Shao et al. 2016).

\subsubsection{NMHCs Characteristics in Non-Haze and Haze Days}

According to the haze day standard of China Meteorological Administration (CMA 2010) and the definitions of Wei et al. (2018), this study recognized a day with daily $\mathrm{PM}_{2.5}>75 \mu \mathrm{g} \mathrm{m}^{-3}$, visibility $<10 \mathrm{~km}$, and relative humidity $<80 \%$ as a haze day. During the monitoring period, about $43.5 \%$ days were recognized as haze days, including 5 days in autumn and 22 days in winter. Comparing the air quality in haze days to that in non-haze days, NMHCs and

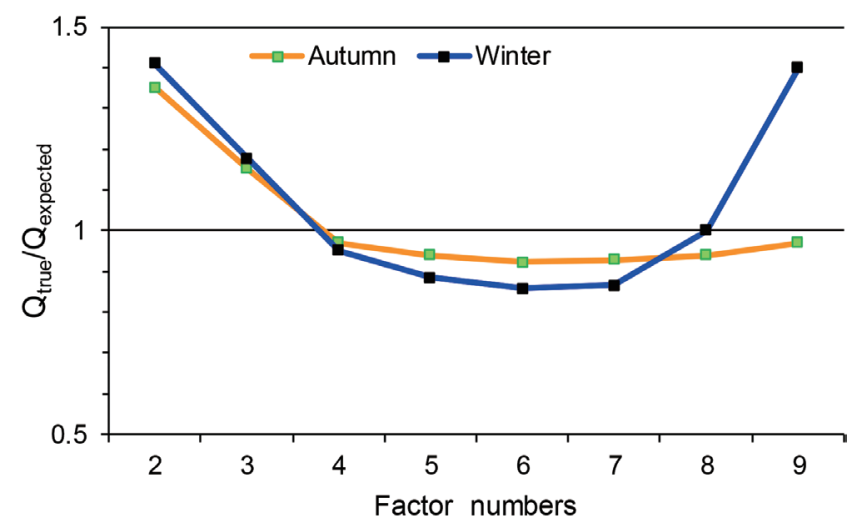

Fig. 2. Variations between Qtrue/Qexpected ratios and factor numbers. 


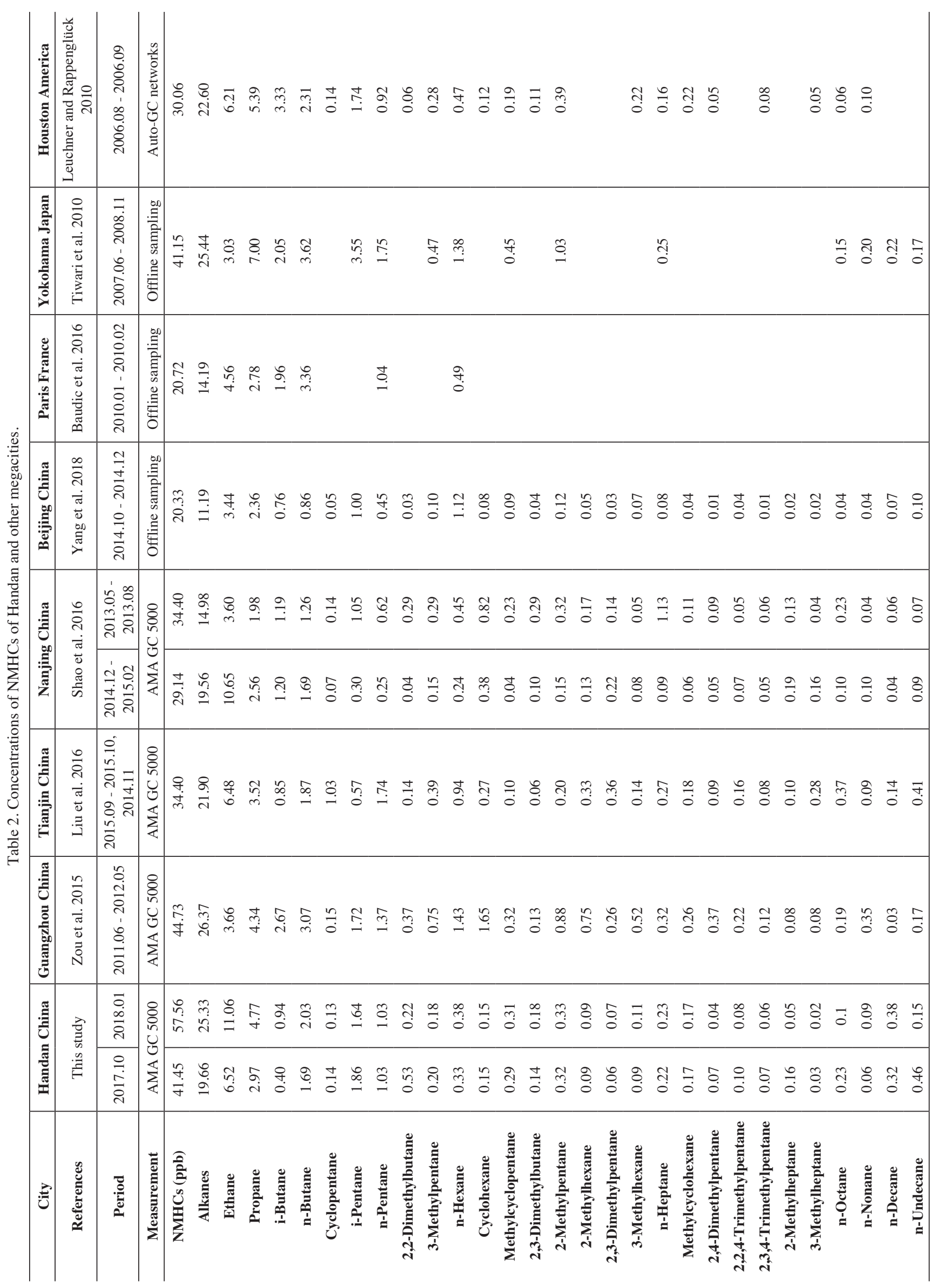




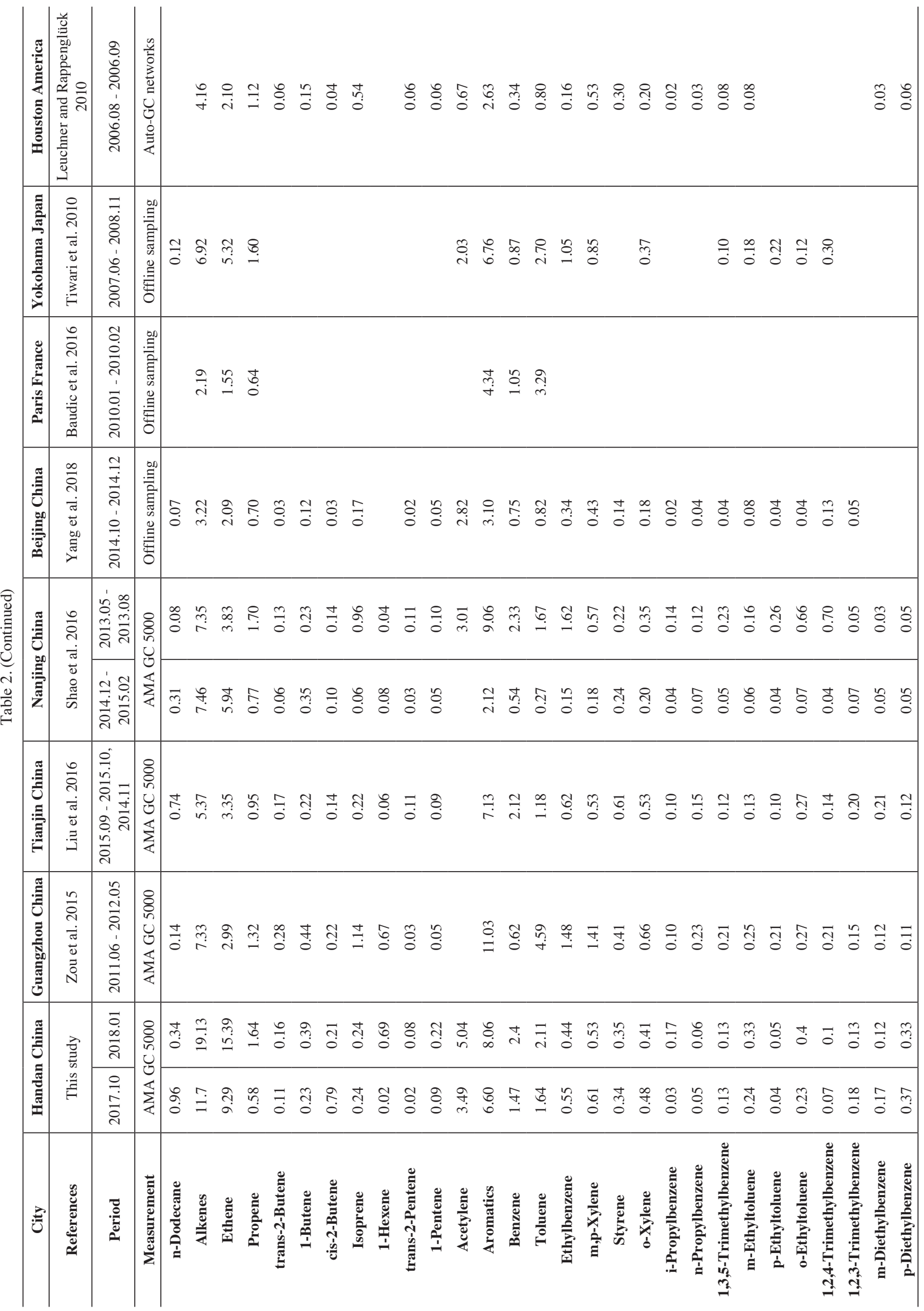




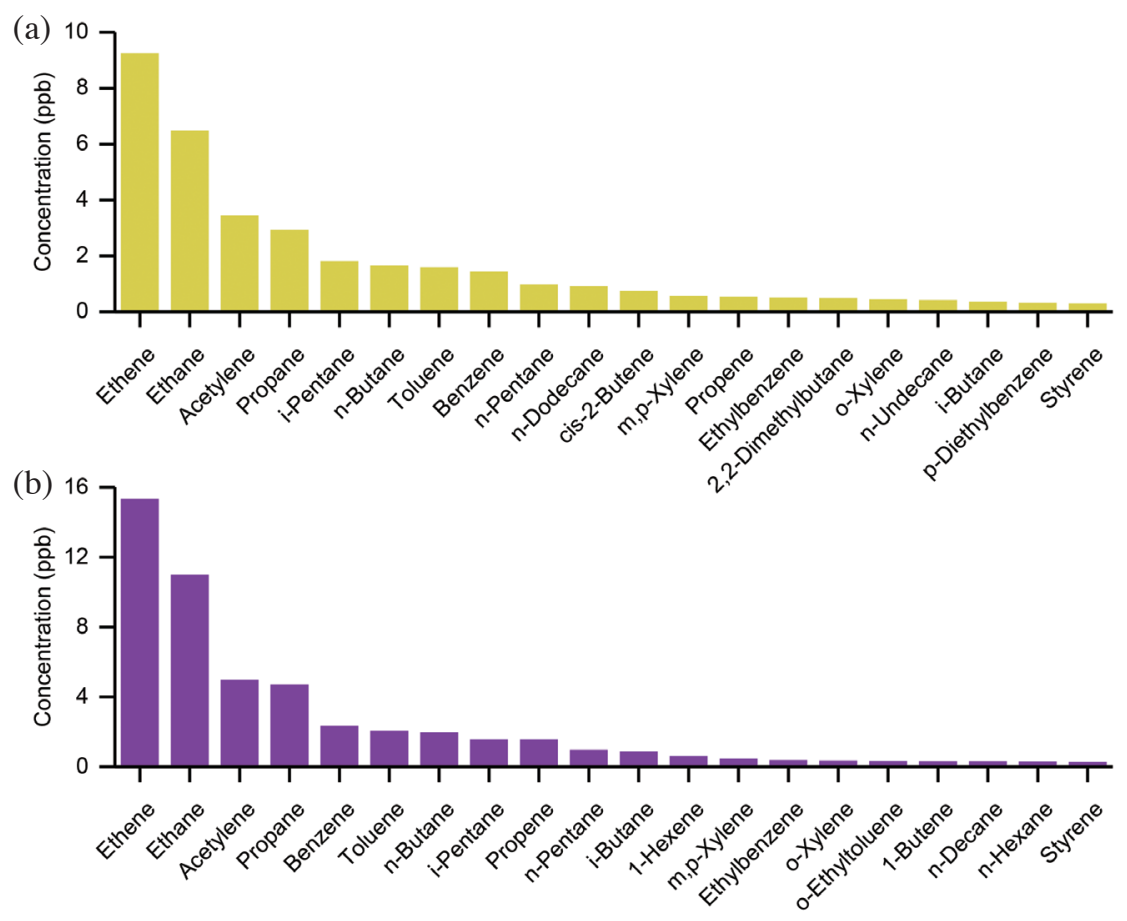

Fig. 3. Top 20 abundant species of Handan in (a) autumn and (b) winter.

$\mathrm{PM}_{2.5}$ had a considerable increase in the monitoring period (Table 3). $\mathrm{PM}_{25}$ concentrations increased about $45.7 \%$ in autumn and $165.3 \%$ in winter, and CO increased $11.3 \%$ in autumn and $85.6 \%$ in winter. Relative low differences were found in NMHCs, with an increase of $8.0 \%$ in autumn and $79.4 \%$ in winter. Generally, concentration differences of NMHCs and $\mathrm{PM}_{2.5}$ in the process of non-haze to haze were larger in winter than in autumn.

Similar patterns were found in NMHCs categories (Fig. 4a). The detail concentrations of these categories were shown in Table 3. Overall, the increases of concentrations and percentages in haze days was higher in winter than those in autumn. Acetylene had the largest difference, with an increase of $37.3 \%$ for autumn and $162.3 \%$ for winter. Alkanes and alkenes increased 5.0 and $8.8 \%$ in autumn, and 76.0 and $62.5 \%$ in winter, respectively. Aromatics had little increase $(0.6 \%)$ in autumn and increased about $97.7 \%$ in winter. However, compared to non-haze days, their proportions in total NMHCs in haze days had a little variation in autumn, and the proportions of alkenes and acetylene in haze days had a slight decrease and increase in winter, respectively. Wei et al. (2018) analyzed the NMHCs differences of Beijing in December using the same criteria for haze days, and they found the increases of 258.8, 422.9, 353.2, 477.0, and $324.1 \%$ for alkanes, alkenes, acetylene, aromatics, and total NMHCs, respectively. The difference between Wei et al. (2018) and our results may be due to the different intensities of source emissions and meteorological conditions.

Figures $4 \mathrm{~b}$ - c summarizes concentration differences and changes of top 20 species in haze days comparing to those in non-haze days. In autumn, the concentration difference of acetylene was the largest (1.23 ppb), with an increase of $37.3 \%$. The concentration of n-dodecane decreased, with a difference of $-0.44 \mathrm{ppb}(-42.5 \%)$, and propane had obvious increase $(0.34 \mathrm{ppb}, 11.6 \%)$ in haze days. Concentration of ethene had slight rise (0.90 ppb, $9.8 \%)$, indicating its stable contribution to NMHCs in autumn. Benzene and ethylbenzene also had increases in haze days of $0.26 \mathrm{ppb}$ $(17.9 \%)$ and $0.07 \mathrm{ppb}(12.4 \%)$. In winter, all the top 20 species increased from non-haze to haze days, ranged at 0.05 - $6.36 \mathrm{ppb}$. Among alkanes species, ethane and propane had the largest increase of $4.57 \mathrm{ppb}(58.5 \%)$ and $2.36 \mathrm{ppb}$ (76.5\%), respectively. Besides, i-butane, n-butane, i-pentane, n-pentane had large increase in haze days, with the range of $100.9-161.0 \%$. Ethene increased about $6.36 \mathrm{ppb}$ $(58.5 \%)$ and acetylene rose about $3.80 \mathrm{ppb}(162.3 \%)$ in haze days. Benzene and toluene increased $1.45 \mathrm{ppb}(105.7 \%)$ and $1.23 \mathrm{ppb}(98.9 \%)$ in haze days. It can be seen that most species showed an increase in haze days, which is partially due to the adverse meteorological conditions (e.g., low wind speed, poor visibility, etc.) that slowed down the photochemical reactions (Liu et al. 2018; Zhao et al. 2019).

\subsubsection{Chemical Degradation of NMHCs in Non-Haze and Haze Days}

Meteorological parameters in monitoring period are shown in Fig. 5. Visibility (VIS) in all the monitoring days 
Table 3. Concentrations and differences in percentage of NMHCs and $\mathrm{PM}_{2.5}$ of Handan in haze and non-haze days.

\begin{tabular}{|c|c|c|c|c|c|c|}
\hline & \multicolumn{3}{|c|}{ Autumn } & \multicolumn{3}{|c|}{ Winter } \\
\hline & \multicolumn{2}{|c|}{ Concentration (Proportion) } & \multirow{2}{*}{ Differences (\%) } & \multicolumn{2}{|c|}{ Concentration (Proportion) } & \multirow{2}{*}{ Differences (\%) } \\
\hline & Non-haze & Haze & & Non-haze & Haze & \\
\hline NMHCs (ppb) & 40.92 & 44.18 & 8.0 & 36.76 & 65.96 & 79.4 \\
\hline Alkanes (ppb) & $19.49(47.6 \%)$ & $20.47(46.3 \%)$ & 5.0 & $16.43(44.7 \%)$ & $28.92(43.8 \%)$ & 76.0 \\
\hline Alkenes (ppb) & $11.54(28.2 \%)$ & $12.56(28.4 \%)$ & 8.8 & $13.23(36.0 \%)$ & $21.50(32.6 \%)$ & 62.5 \\
\hline Acetylene (ppb) & $3.29(8.0 \%)$ & $4.52(10.2 \%)$ & 37.3 & $2.34(6.4 \%)$ & $6.15(9.3 \%)$ & 162.3 \\
\hline Aromatics (ppb) & $6.60(16.1 \%)$ & $6.63(15.0 \%)$ & 0.6 & $4.75(12.9 \%)$ & $9.40(14.3 \%)$ & 97.7 \\
\hline $\mathbf{P M}_{2.5}\left(\mu \mathrm{g} \mathrm{m}^{-3}\right)$ & 77.87 & 113.45 & 45.7 & 56.98 & 151.18 & 165.3 \\
\hline $\mathrm{CO}\left(\mathrm{mg} \mathrm{m}^{-3}\right)$ & 1.11 & 1.23 & 11.3 & 1.34 & 2.48 & 85.6 \\
\hline
\end{tabular}
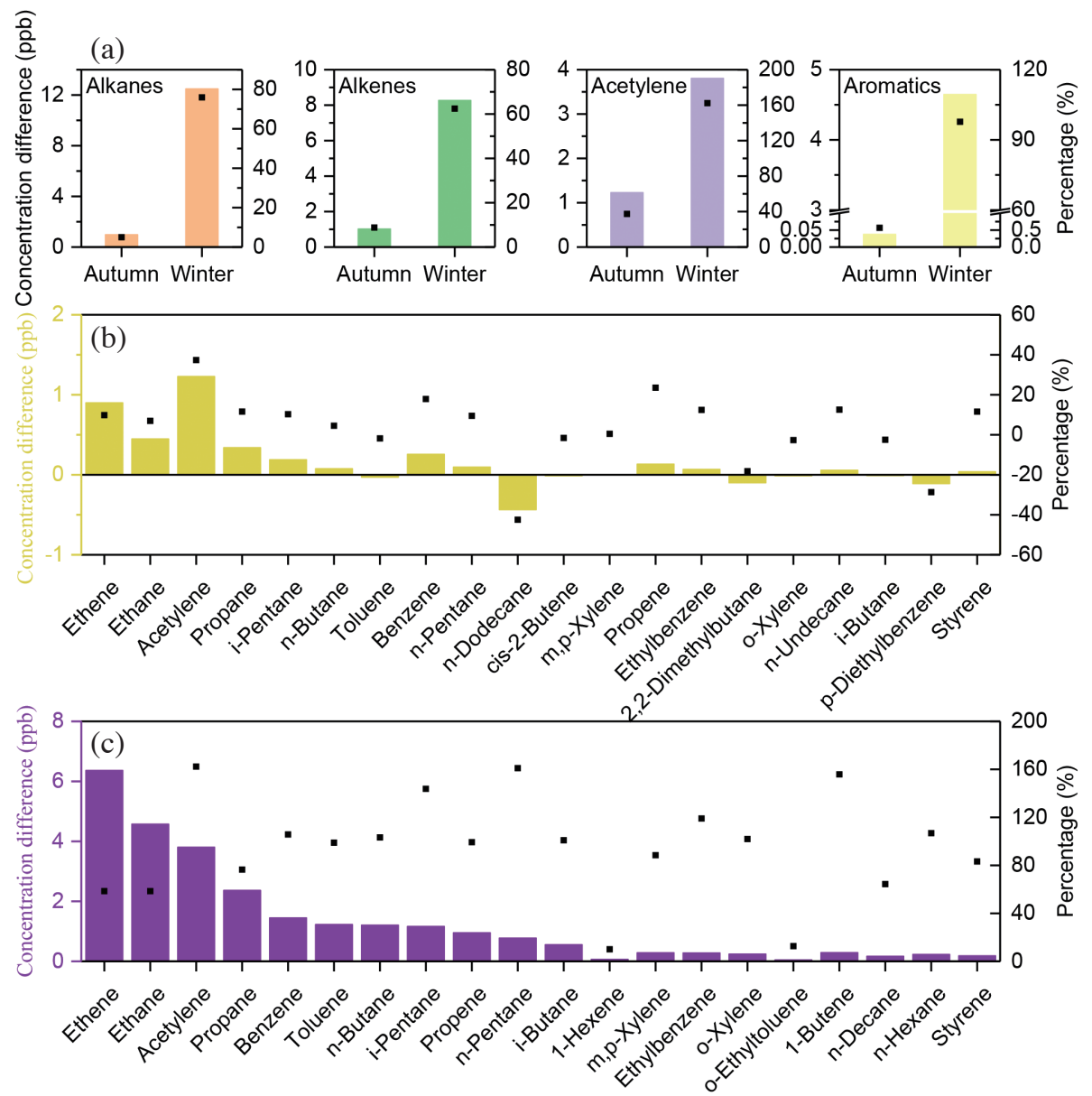

Fig. 4. (a) Concentration differences in haze and non-haze days and changes of four categories; the top 20 species in (b) autumn and (c) winter in Handan. 


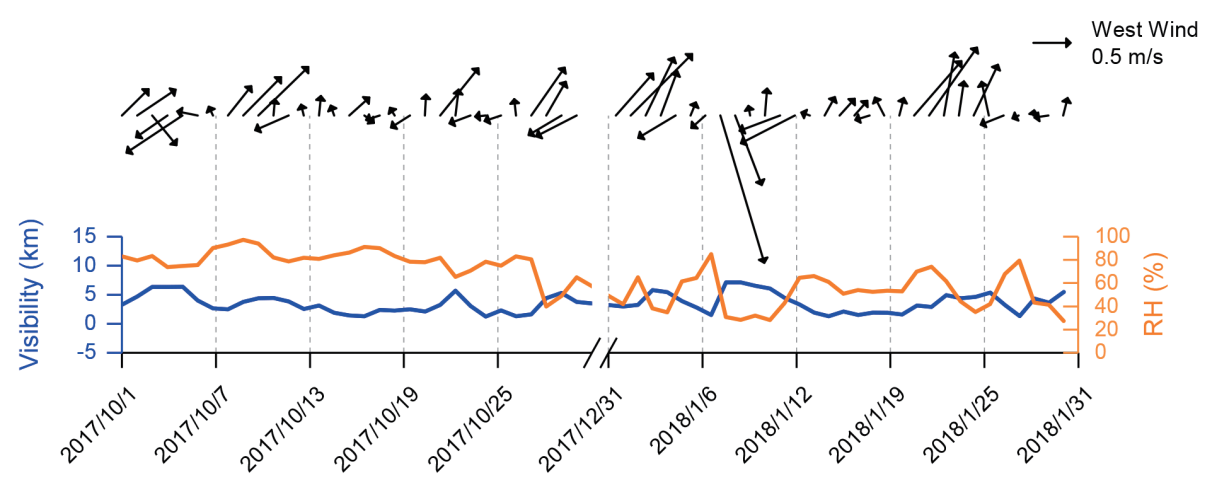

Fig. 5. Wind speed and direction, RH, and visibility in monitoring period in Handan.

were less than $10 \mathrm{~km}$ and daily average relative humidity $(\mathrm{RH})$ was $65.2 \%$. The wind speed in Handan varied at 0.07 $-2.05 \mathrm{~m} \mathrm{~s}^{-1}$ and the frequency of calm wind is as high as $21 \%$. In $95 \%$ of the monitoring days, wind speed was under $1 \mathrm{~m} \mathrm{~s}^{-1}$. In summary, meteorological parameters of Handan showed a stable atmosphere which would suppresses the diffusion of pollutants.

According to Wei et al. (2018), typical single-peak diurnal pattern of $\mathrm{OH}$ and $\mathrm{O}_{3}$ oxidants in atmosphere could lead to the single-valley trend of NMHCs daily variation, if source emissions of NMHCs can be seen in a stable level in the same season. $\mathrm{CO}$ was considered as a chemical stable substance with a lifetime of several months and always used to estimate the age of air mass and chemical reaction in atmosphere (Tie et al. 2013; Zhao et al. 2019). Daily variations of NMHCs and categories of Handan in autumn and winter were presented in Fig. 6. We found that the concentrations of NMHCs and four categories had similar trends. The lowest concentration was measured at 22:00 in autumn and at 13:00 in winter. Therefore, it is reliable to use the ratio of $\mathrm{NMHCs} / \mathrm{CO}$ to explore the chemical reaction in monitoring periods.

We introduced $R C \_d_{\text {haze/nonhaze }}$ to reflect the chemical reaction and physical transport between non-haze and haze process (Wei et al. 2018). In Eq. 6, the (NMHC/CO_d) $)_{\text {nonhaze }}$ and $\left(\mathrm{NMHC} / \mathrm{CO} \_\mathrm{d}\right)_{\text {haze }}$ represent the ratio of $\mathrm{NMHC} / \mathrm{CO}$ in haze and non-haze days. $\mathrm{N}_{\text {nonhaze }}$ and $\mathrm{N}_{\text {haze }}$ mean the number of non-haze and haze days. When RC_ $d_{\text {haze/nonhaze }}$ is negative and drops linearly with $\mathrm{K}_{\mathrm{OH}}$ (rate constant of NMHCs species react with $\mathrm{OH}$ radicals at $298 \mathrm{~K}$ ), it suggests that chemical degradation of NMHCs was enhanced by oxidation reaction. And if the $\mathrm{RC} \_\mathrm{d}_{\text {haze/nonhaze }}$ is completely opposite to that situation, it indicates the chemical degradation of NMHCs was reduced (Wei et al. 2018).

$$
\begin{aligned}
& \mathrm{RC} \_\mathrm{d}_{\text {haze/nonhaze }}= \\
& {\left[\frac{\sum\left(\mathrm{NMHC} / \mathrm{CO} \_\mathrm{d}\right)_{\text {haze }} / \mathrm{N}_{\text {haze }}}{\sum\left(\mathrm{NMHC} / \mathrm{CO} \_\mathrm{d}\right)_{\text {nonhaze }} / \mathrm{N}_{\text {nonhaze }}}-1\right] \times 100 \%}
\end{aligned}
$$

Relations between RC_d $\mathrm{d}_{\text {haze/nonhaze }}$ and $\mathrm{K}_{\mathrm{OH}}$ of NMHCs species is shown in Fig. 7. In autumn, RC_d $\mathrm{d}_{\text {hazennhhaze }}$ of most species were negative with an average value of $-8.9 \%$. The RC_ $\mathrm{d}_{\text {haze/nonhaze }}$ of most alkanes and alkenes were negative, ranged at -63.9 to $-0.8 \%$ and -32.3 to $-9.1 \%$, respectively. Aromatics expect benzene, ethylbenzene, and n-propylbenzene were all negative (-57.8 to $-7.6 \%)$. The $\mathrm{RC} \_\mathrm{d}_{\text {haze/nonhaze }}$ dropped linearly with $\mathrm{K}_{\mathrm{OH}}$, indicating that the chemical reaction was enhanced by oxidation. Whereas the RC_d $d_{\text {haze/nonhaze }}$ of most species were positive in winter. About $60 \%$ of RC_ $\mathrm{d}_{\text {haze/nonhaze }}$ of alkanes and alkenes species were positive, with the ranges of $2.1-70.8 \%$ and 2.3 - $83.8 \%$. The RC_ $d_{\text {haze/nonhaze }}$ of acetylene was $36.0 \%$ and most aromatics were positive (1.4 - 66.0\%) expect styrene, i-propylbenzene, m-ethyltoluene, and o-ethyltoluene. The RC_d $\mathrm{d}_{\text {haze/nonhaze }}$ increased linearly with $\mathrm{K}_{\mathrm{OH}}$. This suggested chemical degradation was reduced in winter. Accordingly, enhanced degradation in autumn and weakened degradation in winter were detected between non-haze and haze days. Wei et al. (2018) estimated the VOCs chemical degradation evaluation of Beijing, and found no obvious trend of VOC degradation in December, which is similar to our results. This may be due to the low temperature and weak photochemical reaction in winter (Ran et al. 2009; Li et al. 2020).

\subsection{Secondary Organic Aerosol Formation}

Volatile organic compounds are important precursors of SOA. Generally, the SOA are considered to be dominated by aromatics (benzene, toluene, etc.) and terpenes ( $\alpha$-pinene, $\beta$-pinene, and isoprene) (Hui et al. 2019). However, some terpenes are not measured in this study, which may cause an underestimation of our SOAP results. So, it is notable that the SOA mentioned in this study referred to was generated by the measured NMHC species. The SOAP developed by. Derwent et al. (2010) was used to estimate the total SOAP.

Figure 8 shows the total SOAP concentrations and the distributions of four NMHCs categories. The total SOAP 
(a)

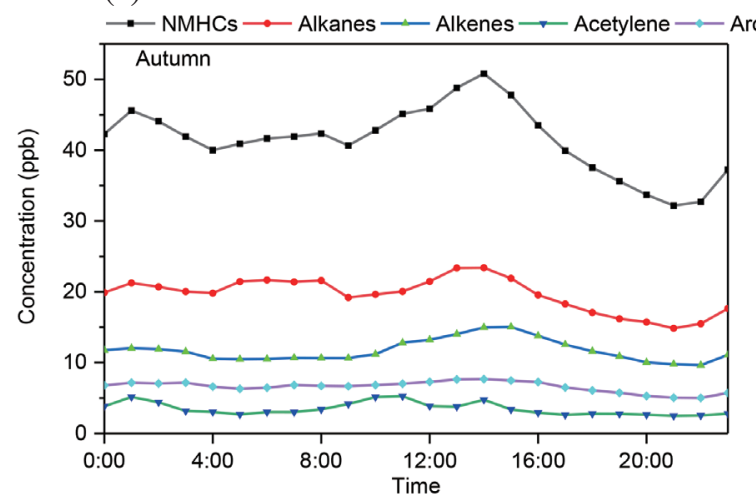

(b)

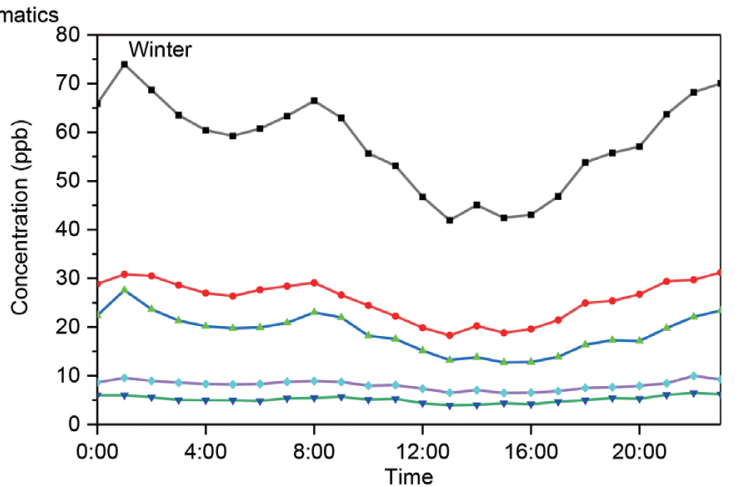

Fig. 6. Diurnal variations of NMHCs, alkanes, alkenes, acetylene, and aromatics in (a) autumn and (b) winter in Handan.

(a)

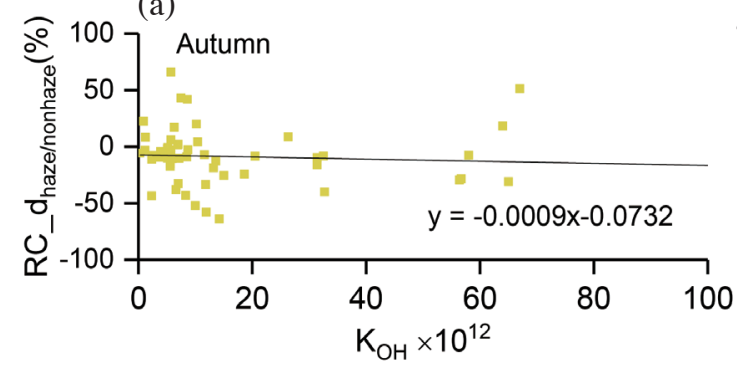

(b)

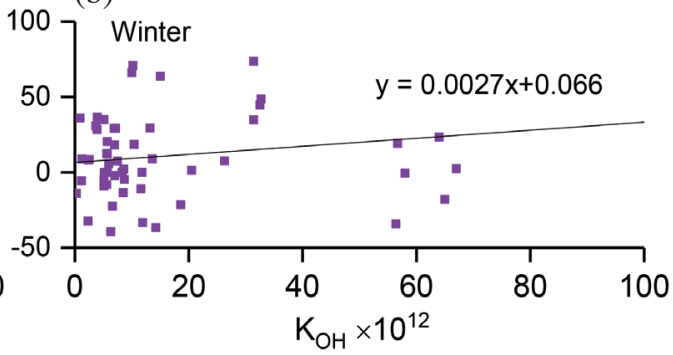

Fig. 7. Correlation of $\mathrm{K}_{\mathrm{OH}}$ and RC_d $\mathrm{d}_{\text {haze/nonhaze }}$ in (a) autumn and (b) winter.

(a)

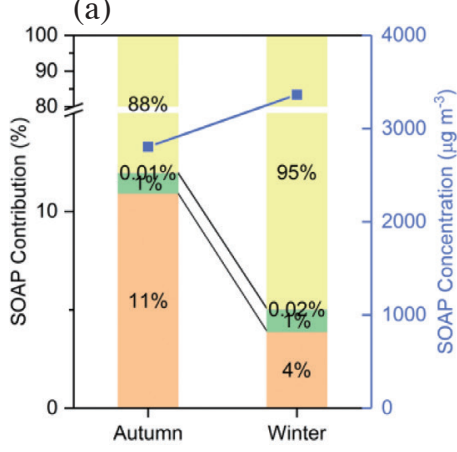

(b)

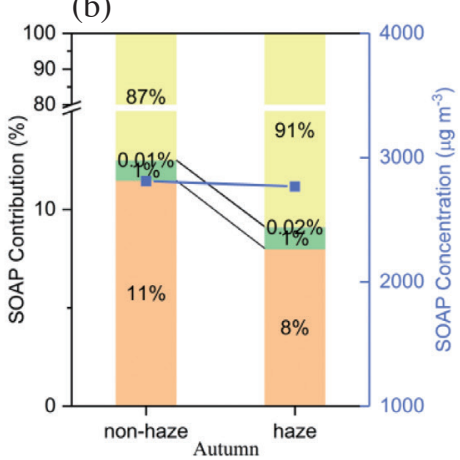

(c)

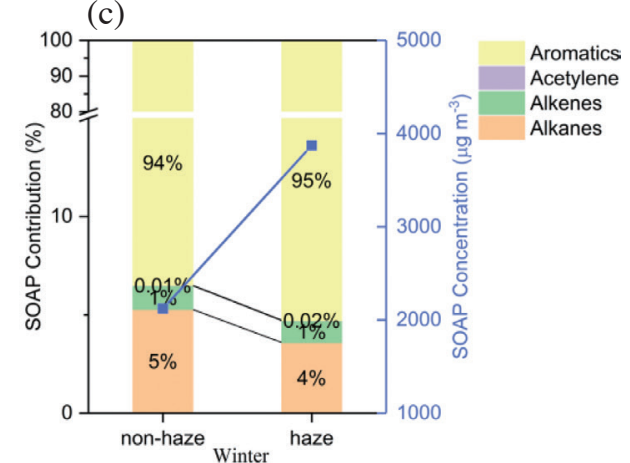

Fig. 8. SOAP distributions (\%) of NMHC categories and SOAP concentrations in different periods; (a) autumn and winter; (b) haze and non-haze days in autumn; (c) haze and non-haze days in winter. 
in winter $\left(3364 \mu \mathrm{g} \mathrm{m}^{-3}\right)$ was higher than that in autumn (2804 $\mu \mathrm{g} \mathrm{m}^{-3}$ ). This result is similar to $\mathrm{Li}$ et al. (2020). The total SOAP showed different variations in non-haze and haze days. The total SOAP concentration in non-haze $\left(2811 \mu \mathrm{g} \mathrm{m}^{-3}\right)$ were close to that in haze days $\left(2768 \mu \mathrm{g} \mathrm{m}^{-3}\right)$ in autumn, however, the concentration was much higher in haze days $\left(3872 \mu \mathrm{g} \mathrm{m}^{-3}\right)$ than that in non-haze days $\left(2121 \mathrm{\mu g} \mathrm{m}^{-3}\right)$ in winter. The distributions of four categories were similar in different periods. Aromatics contributed most to the total SOAP, with a contribution of $87-95 \%$, and followed by alkanes ( $4-11 \%)$, alkenes (-1\%), and acetylene $(<0.1 \%)$. Compared to non-haze days, variations of four categories in haze days in autumn and winter were similar. The contribution of alkanes in haze days $(8.0 \%$ for autumn and $3.6 \%$ for winter) was lower than that in non-haze days (11.5\% for autumn and $5.3 \%$ for winter). In contrast, the contribution of aromatics in haze days (90.9\% for autumn and $95.3 \%$ for winter) were higher than those in non-haze days (87.5\% for autumn and $93.5 \%$ for winter). Generally, the SOAP was higher in haze days than in non-haze days. In haze days, unfavorable meteorology leads to more rapid accumulation of atmospheric gaseous and PM pollutants, including NMHCs, which results in higher SOAP. And higher SOAP may further cause more production of SOA and raise the $\mathrm{PM}_{2.5}$ concentrations.

Table 4 shows the top 10 species that contributed most to the total SOAP in autumn and winter and their SOAP concentrations in non-haze and haze days. There were 9 species belonged to aromatics and only $\mathrm{n}$-dodecane belonged to alkanes. Toluene was the largest contributor to the total SOAP concentration, which is similar to previous studies (Yuan et al. 2013; Sun et al. 2016; Li et al. 2020). Compared to autumn, the SOAP concentration of most aromatics increased and that of u-dodecane decreased in winter. The increase of benzene was $71.5 \%\left(323.8 \mu \mathrm{g} \mathrm{m}^{-3}\right)$, which is the highest among the top 10 species, and followed by m-ethyltoluene, o-ethyltoluene, toluene, and styrene. The decrease of n-do- decane was $-131.2 \%$, with a decrease of $-147.7 \mu \mathrm{g} \mathrm{m}^{-3}$. In autumn, the contributions of n-dodecane and o-ethyltoluene to the total SOAP concentration had large differences in haze days compared to those in non-haze days, with changes of 42.8 and $35.5 \%$. In winter, the contributions of all the 10 species in non-haze days were lower than those in haze days, with differences in the range of $0-116.5 \%$.

\subsection{NMHCs Source Apportionment}

\subsubsection{Diagnostic Ratios}

The study used diagnostic ratios and PMF model to analyze sources of NMHCs. Previous studies indicated that the NMHCs emission sources can be estimated by inter-specific ratios (Tiwari et al. 2010; Kumar et al. 2018). The main depletion of benzene and toluene in ambient atmosphere was due to their photochemical reaction with $\mathrm{OH}$ (Gelencsér et al. 1997). The rate constants of benzene and toluene with $\mathrm{OH}$ were $1.22 \times 10^{-12}$ and $5.63 \times 10^{-12}$. As $\mathrm{T} / \mathrm{B}<2.0$, the sources were more contributed by vehicle exhausts (Niu et al. 2012; Hui et al. 2018; Sheng et al. 2018). In addition, because of the atmosphere lifetimes of ethylbenzene, m-xylene, p-xylene were 1.6 days, 11.8 hours, and 19.4 hours when assuming the $\mathrm{OH}$ was $10^{6} \mathrm{rad} \mathrm{cm}^{-3}$ (Monod et al. 2001), the E/X ratios (ethylbenzene/m,p-xylene) can be used to assess the consumption of $\mathrm{m}, \mathrm{p}$-xylene due to chemical reaction (Hui et al. 2019).

The BTEX ratio (benzene: toluene: ethylbenzene: xylene) was widely used in previous studies to compare NMHCs emission sources of different sampling locations (Khoder 2007). It should be noted that xylene here was the sum of m-xylene, $\mathrm{p}$-xylene, and o-xylene. The ratio of Handan was 2.67:2.97:1:1.98 in autumn, suggesting it may be mainly contributed by traffic emission (Zhang et al. 2016). The ratio in winter was 5.49:4.84:1:2.14, which was very different from other cities in China, e.g., Guangzhou (2.9:4.3:1:4.6), Macau (1.4:3.5:1:4), and Nanhai

Table 4. Summary of the top 10 species that contribute most to the total SOAP.

\begin{tabular}{|c|c|c|c|c|c|c|c|}
\hline \multicolumn{4}{|c|}{ Autumn } & \multicolumn{4}{|c|}{ Winter } \\
\hline Species & non-haze $\left(\mu \mathrm{g} \mathrm{m}^{-3}\right)$ & haze $\left(\mu \mathrm{g} \mathrm{m}^{-3}\right)$ & Change (\%) & Species & non-haze $\left(\mu \mathrm{g} \mathrm{m}^{-3}\right)$ & haze $\left(\mu \mathrm{g} \mathrm{m}^{-3}\right)$ & Change (\%) \\
\hline Toluene & 643 & 629 & 2.2 & Toluene & 516 & 1013 & -96.4 \\
\hline Benzene & 441 & 516 & -17.2 & Benzene & 447 & 911 & -103.7 \\
\hline Styrene & 308 & 342 & -11.1 & Styrene & 220 & 398 & -80.9 \\
\hline Ethylbenzene & 272 & 304 & -11.9 & Ethylbenzene & 126 & 274 & -116.5 \\
\hline n-Dodecane & 255 & 146 & 42.8 & m,p-Xylene & 131 & 244 & -86.3 \\
\hline m,p-Xylene & 233 & 232 & 0.1 & o-Ethyltoluene & 188 & 210 & -11.7 \\
\hline o-Xylene & 207 & 201 & 3.2 & o-Xylene & 108 & 215 & -99.4 \\
\hline m-Ethyltoluene & 126 & 115 & 8.9 & m-Ethyltoluene & 143 & 192 & -33.9 \\
\hline o-Ethyltoluene & 119 & 77 & 35.2 & n-Dodecane & 87 & 91 & -4.7 \\
\hline n-Undecane & 49 & 55 & -12.1 & i-Propylbenzene & 72 & 95 & -31.2 \\
\hline
\end{tabular}


(6.7:14.4:1:4.7) (Wang et al. 2002). The T/B ratios in autumn and winter were $0.62-2.16$ and $0.51-1.49$ and their average values were 1.20 and 0.92 , respectively. This indicated the surroundings of the location may mainly from the emission of vehicle (Niu et al. 2012; Hui et al. 2018; Sheng et al. 2018). The E/X ratio of Handan were 0.51 and 0.46 in autumn and winter, respectively, which is comparable to previous studies (0.22 - 0.93) (Monod et al. 2001; Tiwari et al. 2010), indicating photochemical reaction in autumn was more enhanced than that in winter (Ho et al. 2009).

\subsubsection{PMF Results}

We excluded the species with more than $25 \%$ missing values before running the PMF model and eliminated the influence of species that not fit the model. About 32 and 26 species were selected for PMF analysis for autumn and winter, respectively. Factor profiles and source contributions are presented in Fig. 9.

Factor 1 is identified as high percentage of isoprene both in autumn (68.8\%) and winter (100\%), which always was used to indicate biogenic emission (Guo et al. 2004b; Buzcu and Fraser 2006). However, the monitoring periods were autumn and winter in which the vegetation in Handan may not emit large amount of NMHCs. So, it is regarded as the product of industries (Gelencsér et al. 1997; Buzcu and Fraser 2006; Liu et al. 2016; Zhang et al. 2017). Besides, the proportion of $\mathrm{C}_{2}-\mathrm{C}_{5}$ alkenes ranged at $7.4-34.7 \%$, and ethene and propene were mainly emitted from industrial process (Guo et al. 2007; Liu et al. 2016; Shao et al. 2016; $\mathrm{Hu}$ et al. 2018). Aromatics was emitted from the use of solvent, paint, and other industry process (Harley et al. 1992; Buzcu and Fraser 2006; Cai et al. 2010; Baudic et al. 2016). In winter, acetylene contributed about $50.0 \%$, which may emit from industrial heating due to acetylene, ethene, propene, and benzene are indicators of coal combustion (Yang et al. 2018). Therefore, Factor 1 is identified as industrial related and accounted for 20.6 and $24.1 \%$ in autumn and winter, respectively.

Factor 2 is characterized by high contribution of benzene $(68.0 \% ; 50.7 \%)$. Benzene is the major component of biomass and coal combustion and solvent use (Liu et al. 2008; Zhang et al. 2014; Hui et al. 2019). Meanwhile, ethane $(41.5 \% ; 52.0 \%)$, ethene $(42.4 \% ; 70.8 \%)$, acetylene $(18.2 \% ; 23.8 \%)$, propane $(23.1 \% ; 33.8 \%)$, and propene $(19.8 \% ; 36.3 \%)$ are all released from combustion process (Hsu et al. 2018; Hui et al. 2018). So, we concluded benzene in Factor 2 is related to combustion process. It is notable that the contribution of Factor 2 in autumn and winter are 26.2 and $43.9 \%$. High contribution in winter is caused by more coal combustion in heating season in northern China.

$\mathrm{C}_{3}-\mathrm{C}_{10}$ alkanes in Factor 3 account for a large proportion (all over $30 \%$ ) both in autumn and winter. Many studies proved that propane, i-butane, n-butane, i-pentane, and n- pentane were important species in fuel evaporation (Brown et al. 2007; Baudic et al. 2016; Hui et al. 2018; Zheng et al. 2019), and diesel fuel also had a higher abundance of nheptane and methylcyclohexane (Liu et al. 2008). Liu et al. (2008) found that exhaust emissions mainly contain ethene, pentane, benzene, and toluene. Propene is the characteristic products of internal combustion engines (Zhang et al. 2018b). Butene and acetylene also exist in vehicle exhaust emissions (Liu et al. 2008; Shao et al. 2016). In summary, Factor 3 should be identified as vehicle related source, which referred to fuel evaporation and vehicle exhaust. It accounted for 26.5 and $16.7 \%$ in autumn and winter. This may be because the combustion events during heating period in winter diluted vehicle emission contribution.

There were some differences between autumn and winter in Factor 4. In autumn, BTEX and other $>\mathrm{C}_{8}$ aromatics accounted for higher percentage (23.3 - 73.0\%), which was proved rich in solvent utilization and vehicle fuel combustion (Wang et al. 2013; Shao et al. 2016). The average contribution of $\mathrm{C}_{3}-\mathrm{C}_{8}$ alkanes were all exceeded $30.0 \%$, and contributions of propene $(42.2 \%)$ and acetylene $(38.1 \%)$ were high. This indicated Factor 4 in autumn may related to solvent use and vehicle combustion (Cai et al. 2010; An et al. 2014; Sarkar et al. 2017; Hui et al. 2019). In winter, toluene, ethylbenzene, and trimethylbenzene accounted for a considerable proportion (20.2 - 52.5\%) and they always emitted from solvent use (Guo et al. 2004a; Liu et al. 2008; Zhang et al. 2014; Li et al. 2018b). Above all, Factor 4 was attributed to solvent use and vehicle combustion (26.7\%) and solvent use $(15.3 \%)$ in autumn and winter, respectively.

Diagnostic ratios indicated the effect of traffic emission to NMHCs is unneglectable in autumn and winter. PMF model results showed industrial related, combustion process, vehicle related contributed $20.6,26.2,26.5 \%$ and $24.1,43.9,16.7 \%$ to NMHCs in autumn and winter, respectively. Solvent use and vehicle combustion source in autumn and solvent use in winter contributed 26.7 and $15.3 \%$, respectively. In autumn, combustion emission contribution of Handan is higher than that in Beijing (22.3\%), while vehicle related contribution is lower than that in Beijing (41.8\%) (Yang et al. 2018). In winter, source contributions of Handan were similar to those of Beijing in the period of 13 November to 31 December, with the sources of coal/ biomass burning, industrial emission, solvent use, diesel exhaust, gasoline exhaust accounting for 45.1, 25.2, 12.8, 8.7, $8.2 \%$, respectively (Yang et al. 2018). Combined with the results of two methods, NMHCs of Handan was affected by traffic emissions and combustion events.

\subsubsection{Source Contributions of NMHCs in Non-Haze and Haze Days}

Based on the output files of PMF, daily contributions of each factor to NMHCs were calculated (Fig. 10). In autumn, 
(a)
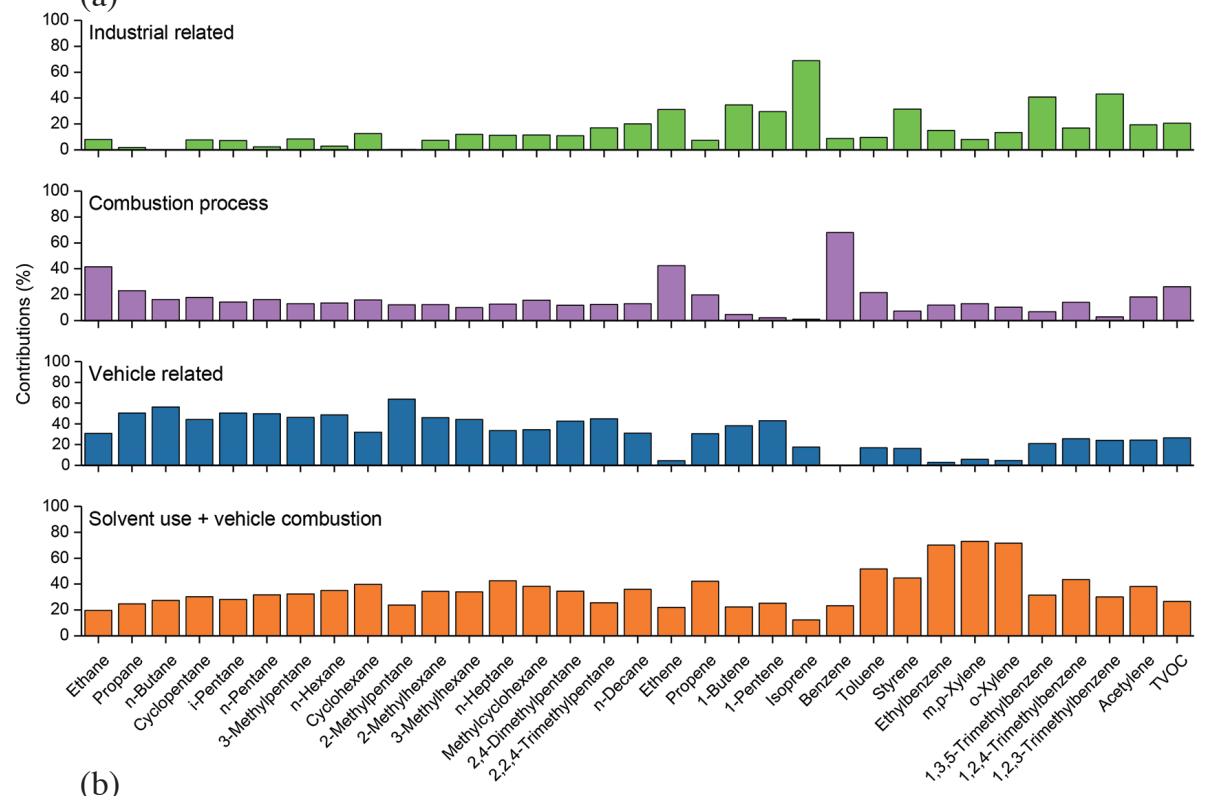

(b)
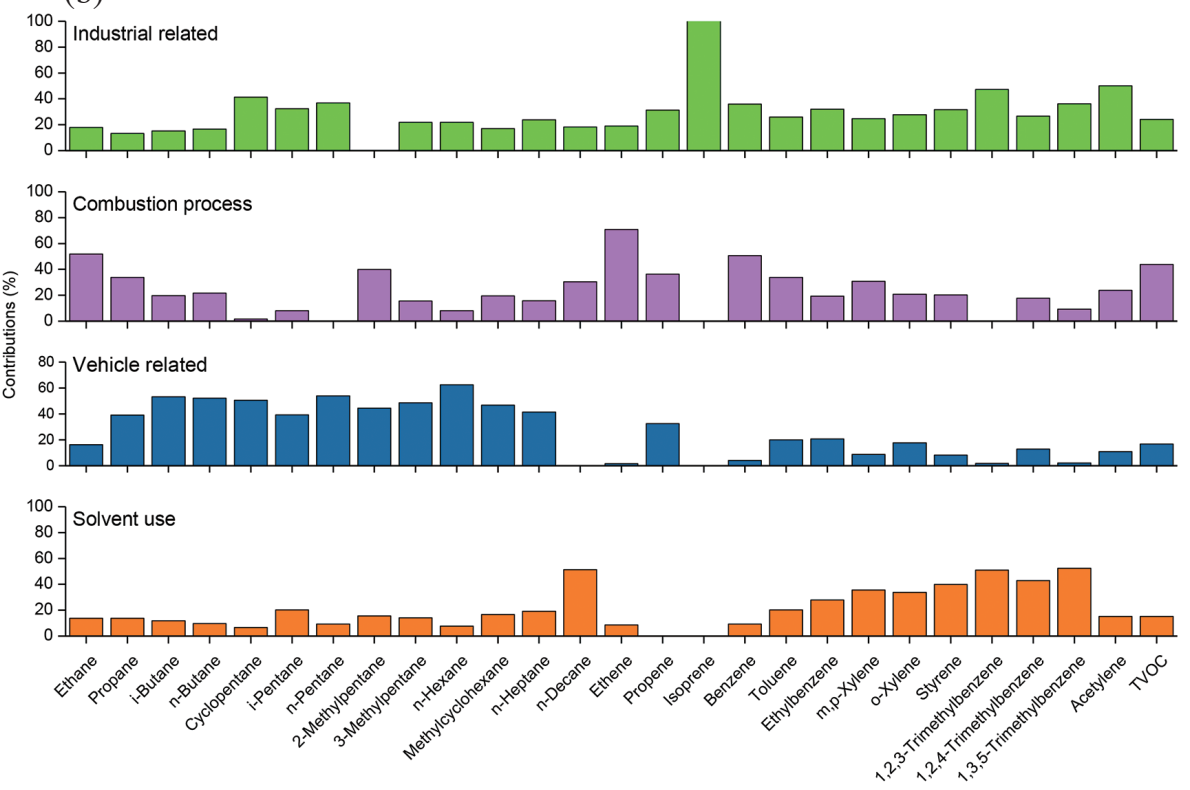

(c)
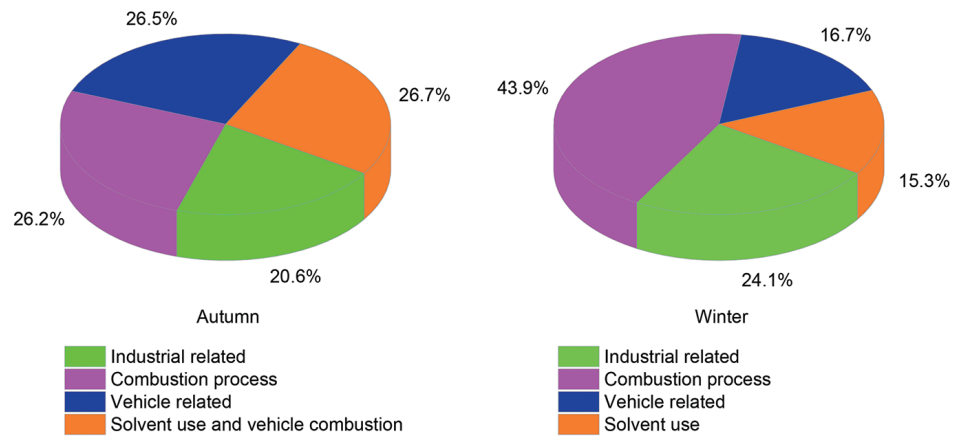

Fig. 9. Source profiles of four factors contributed to NMHCs of Handan from PMF model in (a) autumn and (b) winter, and (c) contributions of sources. 

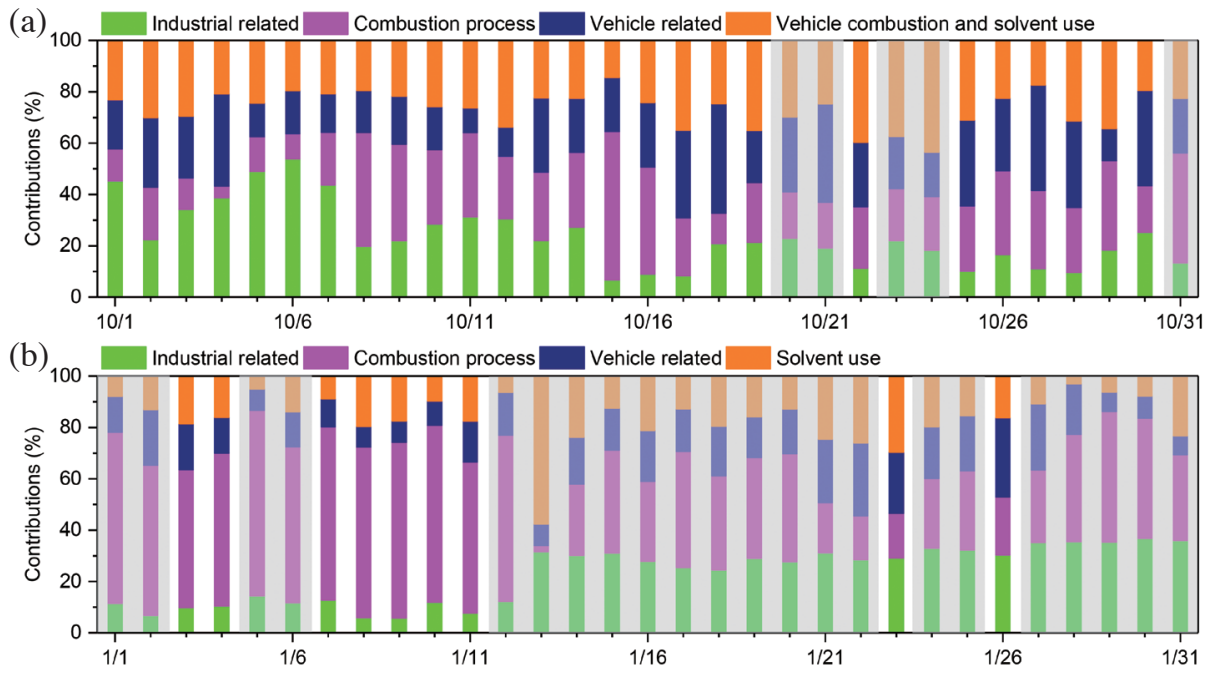

Fig. 10. Daily source contributions to NHMCs of Handan in (a) autumn and (b) winter (haze days were covered with grey bar and non-haze days were white).

contribution of industrial related source in non-haze days $(25.0 \%)$ and haze days $(16.4 \%)$ had the largest difference. Followed by vehicle related source, accounted for $23.2 \%$ in non-haze days and $30.1 \%$ in haze days. The combustion process source accounted for 24.9 and $27.4 \%$ in non-haze and haze days, respectively. Little differences existed in vehicle combustion and solvent use source in non-haze (26.8\%) and haze days $(26.1 \%)$. Therefore, vehicle related source may be one of the major contributors to haze pollution in Handan in autumn. This result was similar to that of Hui et al. (2019), which reported the pollution were closely related to solvent usage in painting/coating, vehicle exhaust and LPG usage.

In winter, combustion process was an important source both in non-haze (17.5 - 69.0\%) and haze (2.4 - 72.4\%) days. From non-haze days to haze days, the contributions of combustion process sources decreased from 53.7 to $40.2 \%$, and those of industrial related source increased from 13.7 to $26.7 \%$. There was no obvious difference between vehicle related and solvent use source in non-haze and haze days. This implied industrial related source may had significant impact on haze pollution in Handan in winter, which is similar to the conclusions of (Sun et al. 2016).

\section{CONCLUSIONS}

This study monitored atmospheric NMHCs in autumn (1 - 31 October 2017) and winter (1 - 31 January 2018) in Handan, one of the top severe polluted cities in northern China. NMHCs pollution characteristics, SOA formation potential, and source apportionment in the two seasons and variations in non-haze and haze days were analyzed and discussed.

During the monitoring periods, NMHCs concentrations in Handan were $41.45 \mathrm{ppb}$ (autumn) and $57.56 \mathrm{ppb}$ (winter), which were higher than those in most reported cities (e.g.,
Beijing, Tianjin China, Paris France, and Houston America). Alkanes was the largest contributor to NMHCs, with an average concentration of $22.47 \mathrm{ppb}$ and accounted for $45.4 \%$, and followed by alkenes (15.40 ppb, 31.1\%), aromatics (7.33 ppb, $14.8 \%$ ), and acetylene (4.27 ppb, 8.6\%). $\mathrm{C}_{2}-\mathrm{C}_{5}$ alkanes, $\mathrm{C}_{2}-\mathrm{C}_{5}$ alkenes, benzene and toluene, acetylene are the most abundant species of the four categories, respectively. In haze days, the concentrations of NMHCs, NMHC categories, $\mathrm{PM}_{2.5}$, and $\mathrm{CO}$ increased far more in winter than those in autumn compared to non-haze days. In haze days, acetylene, $\mathrm{n}$-dodecane, ethene, and benzene had large differences in autumn and ethane, ethene, acetylene, and benzene increased most in winter. The relative changes of $\mathrm{NMHC} / \mathrm{CO}$ ratios in non-haze and haze days and their relative trends to $\mathrm{K}_{\mathrm{OH}}$ indicated enhanced chemical reaction by oxidation in autumn and weakened chemical degradation in winter.

The total SOAP in winter $\left(3364 \mu \mathrm{g} \mathrm{m}^{-3}\right)$ was higher than that in autumn $\left(2804 \mu \mathrm{g} \mathrm{m}^{-3}\right)$. In haze days, the total SOAP was close to non-haze days in autumn, while it was much higher than that in non-haze days in winter. Regardless of the variation of different periods, aromatics contributed most to the total SOAP, with contributions of $87-95 \%$, where toluene was the most contributed species. Alkanes contributed about $4-11 \%$ to the SOAP and n-dodecane was the largest contributor. In haze days, the contribution of alkanes was lower than that in non-haze days while that of aromatics was higher than that in non-haze days.

Diagnostic ratios showed that the effect of traffic emission to NMHCs is unneglectable in autumn and winter. PMF model results showed industrial related, combustion process, vehicle related contributed 20.6, 26.2, 26.5\% and $24.1,43.9,16.7 \%$ to NMHCs in autumn and winter, respectively. Solvent use and vehicle combustion source in autumn and solvent use in winter contributed 26.7 and $15.3 \%$. In 
autumn, industrial related source in non-haze $(25.0 \%)$ and haze days $(16.4 \%)$ had the largest difference and vehicle related may be one of the major sources to haze pollution. In winter, contributions of combustion process (from 53.7 to $40.2 \%$ ) had the largest difference in non-haze and haze days, and industrial related source (from 13.7 to 26.7\%) may had significant impact on haze pollution.

The study had uncertainties in source identifications due to the PMF model, which is partially affected by subjective factors. It is necessary to apply other chemical transport models in the future work, which could identify the local and regional sources, to better support the future policy making.

Acknowledgements This study was sponsored by the National Natural Science Foundation of China (No. 41475131, 41703088), National Key Program of Cause and Control of Severe Air Pollution (No. DQGG-05-09, DQGG-0107, DQGG-02-09, DQGG-03-04), Hebei Science Fund of Distinguished Young Scholars (No. D2017402086), Key Projects of Research and Development of Hebei Province (19273707D), the Program for the Outstanding Young Scholars of Hebei Province, the Hebei Support Program of Hundred Outstanding Innovative Talents from Universities (SLRC2017025), and Hebei Cultivating Project of Talent Development (A2016002022).

\section{REFERENCES}

An, J., B. Zhu, H. Wang, Y. Li, X. Lin, and H. Yang, 2014: Characteristics and source apportionment of VOCs measured in an industrial area of Nanjing, Yangtze River Delta, China. Atmos. Environ., 97, 206-214, doi: 10.1016/j.atmosenv .2014.08.021. [Link]

Baudic, A., V. Gros, S. Sauvage, N. Locoge, O. Sanchez, R. Sarda-Estève, C. Kalogridis, J.-E. Petit, N. Bonnaire, D. Baisnée, O. Favez, A. Albinet, J. Sciare, and B. Bonsang, 2016: Seasonal variability and source apportionment of volatile organic compounds (VOCs) in the Paris megacity (France). Atmos. Chem. Phys., 16, 11961-11989, doi: 10.5194/acp-16-11961-2016. [Link]

Brown, S. G., A. Frankel, and H. R. Hafner, 2007: Source apportionment of VOCs in the Los Angeles area using positive matrix factorization. Atmos. Environ., 41, 227-237, doi: 10.1016/j.atmosenv.2006.08.021. [Link]

Buzcu, B. and M. P. Fraser, 2006: Source identification and apportionment of volatile organic compounds in Houston, TX. Atmos. Environ., 40, 2385-2400, doi: 10.1016/j.atmosenv .2005.12.020. [Link]

Cai, C., F. Geng, X. Tie, Q. Yu, and J. An, 2010: Characteristics and source apportionment of VOCs measured in Shanghai, China. Atmos. Environ., 44, 5005-5014, doi: 10.1016/j.atmosenv .2010.07.059. [Link]

Carter, W. P. L., 1994: Development of Ozone Reactivity Scales for Volatile Organic Compounds. Air \& Waste,
44, 881-899, doi: 10.1080/1073161X.1994.10467290. [Link]

Chang, X., S. Wang, B. Zhao, J. Xing, X. Liu, L. Wei, Y. Song, W. Wu, S. Cai, H. Zheng, D. Ding, and M. Zheng, 2019: Contributions of inter-city and regional transport to $\mathrm{PM}_{2.5}$ concentrations in the Beijing-Tianjin-Hebei region and its implications on regional joint air pollution control. Sci. Total Environ., 660, 11911200, doi: 10.1016/j.scitotenv.2018.12.474. [Link]

Chen, W. T., M. Shao, S. H. Lu, M. Wang, L. M. Zeng, B. Yuan, and Y. Liu, 2014: Understanding primary and secondary sources of ambient carbonyl compounds in Beijing using the PMF model. Atmos. Chem. Phys., 14, 3047-3062, doi: 10.5194/acp-14-3047-2014. [Link]

CMA, 2010: Observation and Forecasting Levels of Haze, QX/T 113-2010, China Meteorological Administration.

Derwent, R. G., M. E. Jenkin, S. R. Utembe, D. E. Shallcross, T. P. Murrells, and N. R. Passant, 2010: Secondary organic aerosol formation from a large number of reactive man-made organic compounds. Sci. Total Environ., 408, 3374-3381, doi: 10.1016/j.scitotenv.2010.04.013. [Link]

Gelencsér, A., K. Siszler, and J. Hlavay, 1997: TolueneBenzene Concentration Ratio as a Tool for Characterizing the Distance from Vehicular Emission Sources. Environ. Sci. Technol., 31, 2869-2872, doi: 10.1021/ es970004c. [Link]

Guo, H., T. Wang, and P. K. K. Louie, 2004a: Source apportionment of ambient non-methane hydrocarbons in Hong Kong: Application of a principal component analysis/absolute principal component scores (PCA/ APCS) receptor model. Environ. Pollut., 129, 489-498, doi: 10.1016/j.envpol.2003.11.006. [Link]

Guo, H., T. Wang, I. J. Simpson, D. R. Blake, X. M. Yu, Y. H. Kwok, and Y. S. Li, 2004b: Source contributions to ambient VOCs and $\mathrm{CO}$ at a rural site in eastern China. Atmos. Environ., 38, 4551-4560, doi: 10.1016/j. atmosenv.2004.05.004. [Link]

Guo, H., K. L. So, I. J. Simpson, B. Barletta, S. Meinardi, and D. R. Blake, 2007: C1-C8 volatile organic compounds in the atmosphere of Hong Kong: Overview of atmospheric processing and source apportionment. Atmos. Environ., 41, 1456-1472, doi: 10.1016/j.atmosenv.2006.10.011. [Link]

Harley, R. A., M. P. Hannigan, and G. R. Cass, 1992: Respeciation of Organic Gas Emissions and the Detection of Excess Unburned Gasoline in the Atmosphere. Environ. Sci. Technol., 26, 2395-2408, doi: 10.1021/ es00036a010. [Link]

Ho, K. F., S. C. Lee, W. K. Ho, D. R. Blake, Y. Cheng, Y. S. Li, S. S. H. Ho, K. Fung, P. K. K. Louie, and D. Park, 2009: Vehicular emission of volatile organic compounds (VOCs) from a tunnel study in Hong Kong. 
Atmos. Chem. Phys., 9, 7491-7504, doi: 10.5194/acp9-7491-2009. [Link]

Hsu, C.-Y., H.-C. Chiang, R.-H. Shie, C.-H. Ku, T.-Y. Lin, M.-J. Chen, N.-T. Chen, and Y.-C. Chen, 2018: Ambient VOCs in residential areas near a large-scale petrochemical complex: Spatiotemporal variation, source apportionment and health risk. Environ. Pollut., 240, 95-104, doi: 10.1016/j.envpol.2018.04.076. [Link]

Hu, D., Q. Bian, T. W. Y. Li, A. K. H. Lau, and J. Z. Yu, 2008: Contributions of isoprene, monoterpenes, $\beta$-caryophyllene, and toluene to secondary organic aerosols in Hong Kong during the summer of 2006. J. Geophys. Res., 113, doi: 10.1029/2008jd010437. [Link]

Hu, K., M. Wang, J. Zheng, H. Wang, X. Lu, S. Jing, and C. Chen, 2018: Quantification of the Influence of Industrial Emissions on Volatile Organic Compounds (VOCs) Using PMF Model: A Case Study of Jiangbei Industrial Zone in Nanjing. Environ. Sci., 39, 493-501, doi: 10.13227/j.hjkx.201708254. [Link]

Huang, R.-J., Y. Zhang, C. Bozzetti, K.-F. Ho, J.-J. Cao, Y. Han, K. R. Daellenbach, J. G. Slowik, S. M. Platt, F. Canonaco, P. Zotter, R. Wolf, S. M. Pieber, E. A. Bruns, M. Crippa, G. Ciarelli, A. Piazzalunga, M. Schwikowski, G. Abbaszade, J. Schnelle-Kreis, R. Zimmermann, Z. An, S. Szidat, U. Baltensperger, I. E. Haddad, and A. S. H. Prévôt, 2014: High secondary aerosol contribution to particulate pollution during haze events in China. Nature, 514, 218-222, doi: 10.1038/nature13774. [Link]

Hui, L., X. Liu, Q. Tan, M. Feng, J. An, Y. Qu, Y. Zhang, and M. Jiang, 2018: Characteristics, source apportionment and contribution of VOCs to ozone formation in Wuhan, Central China. Atmos. Environ., 192, 55-71, doi: 10.1016/j.atmosenv.2018.08.042. [Link]

Hui, L., X. Liu, Q. Tan, M. Feng, J. An, Y. Qu, Y. Zhang, and N. Cheng, 2019: VOC characteristics, sources and contributions to SOA formation during haze events in Wuhan, Central China. Sci. Total Environ., 650, 26242639, doi: 10.1016/j.scitotenv.2018.10.029. [Link]

Kaltsonoudis, C., E. Kostenidou, K. Florou, M. Psichoudaki, and S. N. Pandis, 2016: Temporal variability and sources of VOCs in urban areas of the eastern Mediterranean. Atmos. Chem. Phys., 16, 14825-14842, doi: 10.5194/acp-16-14825-2016. [Link]

Khoder, M. I., 2007: Ambient levels of volatile organic compounds in the atmosphere of Greater Cairo. Atmos. Environ., 41, 554-566, doi: 10.1016/j.atmosenv. 2006.08.051. [Link]

Kleindienst, T. E., M. Jaoui, M. Lewandowski, J. H. Offenberg, C. W. Lewis, P. V. Bhave, and E. O. Edney, 2007: Estimates of the contributions of biogenic and anthropogenic hydrocarbons to secondary organic aerosol at a southeastern US location. Atmos. Environ.,
41, 8288-8300, doi: 10.1016/j.atmosenv.2007.06.045. [Link]

Kumar, A., D. Singh, K. Kumar, B. B. Singh, and V. K. Jain, 2018: Distribution of VOCs in urban and rural atmospheres of subtropical India: Temporal variation, source attribution, ratios, OFP and risk assessment. Sci. Total Environ., 613-614, 492-501, doi: 10.1016/j. scitotenv.2017.09.096. [Link]

Leuchner, M. and B. Rappenglück, 2010: VOC source-receptor relationships in Houston during TexAQS-II. Atmos. Environ., 44, 4056-4067, doi: 10.1016/j.atmosenv.2009.02.029. [Link]

Li, G., W. Wei, X. Shao, L. Nie, H. Wang, X. Yan, and R. Zhang, 2018a: A comprehensive classification method for VOC emission sources to tackle air pollution based on VOC species reactivity and emission amounts. J. Environ. Sci., 67, 78-88, doi: 10.1016/j. jes.2017.08.003. [Link]

Li, J., C. Zhai, J. Yu, R. Liu, Y. Li, L. Zeng, and S. Xie, 2018b: Spatiotemporal variations of ambient volatile organic compounds and their sources in Chongqing, a mountainous megacity in China. Sci. Total Environ., 627, 1442-1452, doi: 10.1016/j.scitotenv.2018.02.010. [Link]

Li, M., Q. Zhang, J. Kurokawa, J.-H. Woo, K. He, Z. Lu, T. Ohara, Y. Song, D. G. Streets, G. R. Carmichael, Y. Cheng, C. Hong, H. Huo, X. Jiang, S. Kang, F. Liu, H. Su, and B. Zheng, 2017a: MIX: A mosaic Asian anthropogenic emission inventory under the international collaboration framework of the MICS-Asia and HTAP. Atmos. Chem. Phys., 17, 935-963, doi: 10.5194/acp17-935-2017. [Link]

Li, Q., G. Su, C. Li, P. Liu, X. Zhao, C. Zhang, X. Sun, Y. Mu, M. Wu, Q. Wang, and B. Sun, 2020: An investigation into the role of VOCs in SOA and ozone production in Beijing, China. Sci. Total Environ., 720, 137536, doi: 10.1016/j.scitotenv .2020.137536. [Link]

Li, Y., M. Chang, S. Ding, S. Wang, D. Ni, and H. Hu, 2017b: Monitoring and source apportionment of trace elements in $\mathrm{PM}_{2.5}$ : Implications for local air quality management. J. Environ. Manage., 196, 16-25, doi: 10.1016/j.jenvman.2017.02.059. [Link]

Liu, B., D. Liang, J. Yang, Q. Dai, X. Bi, Y. Feng, J. Yuan, Z. Xiao, Y. Zhang, and H. Xu, 2016: Characterization and source apportionment of volatile organic compounds based on 1-year of observational data in Tianjin, China. Environ. Pollut., 218, 757-769, doi: 10.1016/j.envpol.2016.07.072. [Link]

Liu, B., Y. Ma, W. Gong, M. Zhang, and J. Yang, 2018: Study of continuous air pollution in winter over $\mathrm{Wu}$ han based on ground-based and satellite observations. Atmos. Pollut. Res., 9, 156-165, doi: 10.1016/j. apr.2017.08.004. [Link]

Liu, Y., M. Shao, L. Fu, S. Lu, L. Zeng, and D. Tang, 2008: 
Source profiles of volatile organic compounds (VOCs) measured in China: Part I. Atmos. Environ., 42, $6247-$ 6260, doi: 10.1016/j.atmosenv.2008.01.070. [Link]

Ma, S., L. Wang, Z. Wei, F. Zhang, C. Meng, and J. Yang, 2016: Characterization of $\mathrm{PM}_{2.5}$ and it's chemical compositions under different air quality grades in Handan, China. Fresenius Environ. Bull., 25, 5162-5171.

Manousakas, M., H. Papaefthymiou, E. Diapouli, A. Migliori, A. G. Karydas, I. Bogdanovic-Radovic, and K. Eleftheriadis, 2017: Assessment of $\mathrm{PM}_{2.5}$ sources and their corresponding level of uncertainty in a coastal urban area using EPA PMF 5.0 enhanced diagnostics. Sci. Total Environ., 574, 155-164, doi: 10.1016/j.scitotenv.2016.09.047. [Link]

Meng, C. C., L. T. Wang, F. F. Zhang, Z. Wei, S. M. Ma, X. Ma, and J. Yang, 2016: Characteristics of concentrations and water-soluble inorganic ions in $\mathrm{PM}_{2.5}$ in Handan City, Hebei province, China. Atmos. Res., 171, 133-146, doi: 10.1016/j.atmosres.2015.12.013. [Link]

Monod, A., B. C. Sive, P. Avino, T. Chen, D. R. Blake, and F. Sherwood Rowland, 2001: Monoaromatic compounds in ambient air of various cities: A focus on correlations between the xylenes and ethylbenzene. Atmos. Environ., 35, 135-149, doi: 10.1016/s13522310(00)00274-0. [Link]

Na, K., Y. P. Kim, K.-C. Moon, I. Moon, and K. Fung, 2001: Concentrations of volatile organic compounds in an industrial area of Korea. Atmos. Environ., 35, 2747 2756, doi: 10.1016/S1352-2310(00)00313-7. [Link]

Niu, Z., H. Zhang, Y. Xu, X. Liao, L. Xu, and J. Chen, 2012: Pollution characteristics of volatile organic compounds in the atmosphere of Haicang District in Xiamen City, Southeast China. J. Environ. Monit., 14, 1145-1152, doi: 10.1039/c2em10884d. [Link]

Paatero, P., 1997: Least squares formulation of robust nonnegative factor analysis. Chemometrics Intell. Lab. Syst., 37, 23-35, doi: 10.1016/S0169-7439(96)00044-5. [Link]

Paatero, P. and U. Tapper, 1994: Positive matrix factorization: A non-negative factor model with optimal utilization of error estimates of data values. Environmetrics, 5, 111-126, doi: 10.1002/env.3170050203. [Link]

Ran, L., C. Zhao, F. Geng, X. Tie, X. Tang, L. Peng, G. Zhou, Q. Yu, J. Xu, and A. Guenther, 2009: Ozone photochemical production in urban Shanghai, China: Analysis based on ground level observations. J. Geophys. Res., 114, D15031, doi: 10.1029/2008jd010752. [Link]

Sarkar, C., V. Sinha, B. Sinha, A. K. Panday, M. Rupakheti, and M. G. Lawrence, 2017: Source apportionment of NMVOCs in the Kathmandu Valley during the SusKat-ABC international field campaign using positive matrix factorization. Atmos. Chem. Phys., 17, 8129-
8156, doi: 10.5194/acp-17-8129-2017. [Link]

Schallhart, S., P. Rantala, M. K. Kajos, J. Aalto, I. Mammarella, T. M. Ruuskanen, and M. Kulmala, 2018: Temporal variation of VOC fluxes measured with PTR-TOF above a boreal forest. Atmos. Chem. Phys., 18, 815-832, doi: 10.5194/acp-18-815-2018. [Link]

Shao, P., J. An, J. Xin, F. Wu, J. Wang, D. Ji, and Y. Wang, 2016: Source apportionment of VOCs and the contribution to photochemical ozone formation during summer in the typical industrial area in the Yangtze River Delta, China. Atmos. Res., 176-177, 64-74, doi: 10.1016/j.atmosres.2016.02.015. [Link]

Sheng, T., X. Chen, S. Gao, Q. Liu, Q. Fu, Z. Gao, and Y. Duan, 2018: Progress in the Research of Application of VOCs Ratio Method. Environ. Sci. Technol., 41, 128-136, doi: 10.19672/j.cnki.1003-6504.2018.12.018. [Link]

Sonderfeld, H., I. R. White, I. C. A. Goodall, J. R. Hopkins, A. C. Lewis, R. Koppmann, and P. S. Monks, 2016: What effect does VOC sampling time have on derived OH reactivity? Atmos. Chem. Phys., 16, 6303-6318, doi: 10.5194/acp-16-6303-2016. [Link]

Song, S.-K. and Z.-H. Shon, 2014: National Emissions of Greenhouse Gases and Air Pollutants from Commercial Aircraft in the Troposphere over South Korea. Terr. Atmos. Ocean. Sci., 25, 61-76, doi: 10.3319/ TAO.2013.09.04.01(A). [Link]

Sun, J., F. Wu, B. Hu, G. Tang, J. Zhang, and Y. Wang, 2016: VOC characteristics, emissions and contributions to SOA formation during hazy episodes. Atmos. Environ., 141, 560-570, doi: 10.1016/j.atmosenv.2016.06.060. [Link]

Tie, X., F. Geng, A. Guenther, J. Cao, J. Greenberg, R. Zhang, E. Apel, G. Li, A. Weinheimer, J. Chen, and C. Cai, 2013: Megacity impacts on regional ozone formation: Observations and WRF-Chem modeling for the MIRAGE-Shanghai field campaign. Atmos. Chem. Phys., 13, 5655-5669, doi: 10.5194/acp-13-5655-2013. [Link]

Tiwari, V., Y. Hanai, and S. Masunaga, 2010: Ambient levels of volatile organic compounds in the vicinity of petrochemical industrial area of Yokohama, Japan. Air Qual. Atmos. Health, 3, 65-75, doi: 10.1007/s11869009-0052-0. [Link]

USEPA, 2014: EPA Positive Matrix Factorization 5.0 Fundamentals and User Guide, U.S. Environmental Protection Agency, $124 \mathrm{pp}$.

Wang, L. T., Z. Wei, J. Yang, Y. Zhang, F. F. Zhang, J. Su, C. C. Meng, and Q. Zhang, 2014: The 2013 severe haze over southern Hebei, China: Model evaluation, source apportionment, and policy implications. Atmos. Chem. Phys., 14, 3151-3173, doi: 10.5194/acp-143151-2014. [Link] 
Wang, Q., C. Chen, H. Wang, M. Zhou, S. Lou, L. Qiao, C. Huang, L. Li, L. Su, Y. Mu, Y. Chen, and M. Chen, 2013: Forming potential of secondary organic aerosols and sources apportionment of VOCs in autumn of Shanghai, China. Environ. Sci., 34, 424-433, doi: 10.13227/j.hjkx.2013.02.028. [Link]

Wang, X., G. Sheng, J. Fu, C. Chan, S.-C. Lee, L. Y. Chan, and Z. Wang, 2002: Urban roadside aromatic hydrocarbons in three cities of the Pearl River Delta, People's Republic of China. Atmos. Environ., 36, 5141-5148, doi: 10.1016/s1352-2310(02)00640-4. [Link]

Wei, W., Y. Li, Y. Wang, S. Cheng, and L. Wang, 2018: Characteristics of VOCs during haze and non-haze days in Beijing, China: Concentration, chemical degradation and regional transport impact. Atmos. Environ., 194, 134-145, doi: 10.1016/j.atmosenv.2018.09.037. [Link]

Yang, W., Y. Zhang, X. Wang, S. Li, M. Zhu, Q. Yu, G. Li, Z. Huang, H. Zhang, Z. Wu, W. Song, J. Tan, and M. Shao, 2018: Volatile organic compounds at a rural site in Beijing: Influence of temporary emission control and wintertime heating. Atmos. Chem. Phys., 18, 1266312682, doi: 10.5194/acp-18-12663-2018. [Link]

Yuan, B., W. W. Hu, M. Shao, M. Wang, W. T. Chen, S. H. Lu, L. M. Zeng, and M. Hu, 2013: VOC emissions, evolutions and contributions to SOA formation at a receptor site in eastern China. Atmos. Chem. Phys., 13, 8815-8832, doi: 10.5194/acp-13-8815-2013. [Link]

Zhang, C., L. Litao Wang, M. Qi, X. Ma, L. Zhao, S. Ji, Y. Wang, X. Lu, Q. Wang, R. Xu, and Y. Ma, 2018a: Evolution of Key Chemical Components in $\mathrm{PM}_{2.5}$ and Potential Formation Mechanisms of Serious Haze Events in Handan, China. Aerosol Air Qual. Res., 18, 1545-1557, doi: 10.4209/aaqr.2017.10.0386. [Link]

Zhang, J., Y. Sun, F. Wu, J. Sun, and Y. Wang, 2014: The characteristics, seasonal variation and source ap- portionment of VOCs at Gongga Mountain, China. Atmos. Environ., 88, 297-305, doi: 10.1016/j.atmosenv.2013.03.036. [Link]

Zhang, Y., J. An, X. Lin, J. Wang, Y. Shi, and J. Liu, 2017: Source Apportionment of Volatile Organic Compounds and Health Assessment of Benzene Series in Northern Suburb of Nanjing in Winter. Environ. Sci., 38, 1-12, doi: 10.13227/j.hjkx.201605170. [Link]

Zhang, Y., R. Li, H. Fu, D. Zhou, and J. Chen, 2018b: Observation and analysis of atmospheric volatile organic compounds in a typical petrochemical area in Yangtze River Delta, China. J. Environ. Sci., 71, 233-248, doi: 10.1016/j.jes.2018.05.027. [Link]

Zhang, Z., Y. Zhang, X. Wang, S. Lü, Z. Huang, X. Huang, W. Yang, Y. Wang, and Q. Zhang, 2016: Spatiotemporal patterns and source implications of aromatic hydrocarbons at six rural sites across China's developed coastal regions. J. Geophys. Res., 121, 6669-6687, doi: 10.1002/2016jd025115. [Link]

Zhao, L., L. Wang, J. Tan, J. Duan, X. Ma, C. Zhang, S. Ji, M. Qi, X. Lu, Y. Wang, Q. Wang, and R. Xu, 2019: Changes of chemical composition and source apportionment of $\mathrm{PM}_{2.5}$ during 2013-2017 in urban Handan, China. Atmos. Environ., 206, 119-131, doi: 10.1016/j. atmosenv.2019.02.034. [Link]

Zheng, S., X. Xu, Y. Zhang, L. Wang, Y. Yang, S. Jin, and $X$. Yang, 2019: Characteristics and sources of VOCs in urban and suburban environments in Shanghai, China, during the 2016 G20 summit. Atmos. Pollut. Res., 10, 1766-1779, doi: 10.1016/j.apr.2019.07.008. [Link]

Zou, Y., X. J. Deng, D. Zhu, D. C. Gong, H. Wang, F. Li, H. B. Tan, T. Deng, B. R. Mai, X. T. Liu, and B. G. Wang, 2015: Characteristics of 1 year of observational data of VOCs, $\mathrm{NO}_{x}$ and $\mathrm{O}_{3}$ at a suburban site in Guangzhou, China. Atmos. Chem. Phys., 15, 6625-6636, doi: 10.5194/acp-15-6625-2015. [Link] 